\title{
HEDGING AND FINANCIAL \\ FRAGILITY IN FIXED \\ EXCHANGE RATE REGIMES
}

Craig Burnside

Martin Eichenbaum

Sergio Rebelo

Working Paper 7143

http://www.nber.org/papers/w7143

\section{NATIONAL BUREAU OF ECONOMIC RESEARCH 1050 Massachusetts Avenue \\ Cambridge, MA 02138 \\ May 1999}

We are grateful to Kellogg's Banking Research Center for financial support. This draft was completed while Burnside was a National Fellow at the Hoover Institution which he thanks for its support. We thank Marco Bassetto, Ariel Burstein, Larry Jones, Deborah Lucas, and David Marshall and seminar participants at Georgetown, Harvard, Hoover, and Northwestern for useful comments. The views expressed herein are those of the authors and do not necessarily reflect the views of the National Bureau of Economic Research or the World Bank.

(C) 1999 by Craig Burnside, Martin Eichenbaum, and Sergio Rebelo. All rights reserved. Short sections of text, not to exceed two paragraphs, may be quoted without explicit permission provided that full credit, including $(\mathcal{C}$ notice, is given to the source. 
Hedging and Financial Fragility in

Fixed Exchange Rate Regimes

Craig Burnside, Martin Eichenbaum, and Sergio Rebelo

NBER Working Paper No. 7143

May 1999

JEL No. F31, F41, G15, G21

\section{ABSTRACT}

Currency crises that coincide with banking crises tend to share four elements. First, governments provide guarantees to domestic and foreign bank creditors. Second, banks do not hedge their exchange rate risk. Third, there is a lending boom before the crises. Finally, when the currency/banking collapse occurs, interest rates rise and there is a persistent decline in output. This paper proposes an explanation for these regularities. We show that government guarantees lower interest rates and generate an economic boom. They also lead to a more fragile banking system; banks choose not to hedge exchange rate risk. When the fixed exchange rate is abandoned in favor of a crawling peg, banks go bankrupt, the domestic interest rate rises, real wages fall, and output declines.

Craig Burnside

The World Bank

1818 H Street, NW

Washington, DC 20433

aburnside@worldbank.org
Martin Eichenbaum

Department of Economics

Northwestern University

2003 Sheridan Rd.

Evanston, IL 60208

and NBER

eich@nwu.edu

Sergio Rebelo

J.L. Kellogg Graduate School of Management

Northwestern University

Leverone Hall

Evanston, IL 60208

and NBER

s-rebelo@nwu.edu 


\section{Introduction}

In the post Bretton Woods era currency crises have often coincided with banking crises. Prominent examples include Southeast Asia in 1997, Chile in 1982, Mexico in 1994, and Sweden and Finland in 1992. ${ }^{1}$ There are four common elements in such 'dual' crises. First, there are implicit government guarantees to domestic and foreign bank creditors. Second, banks do not generally hedge exchange rate risk and many go bankrupt following a currency devaluation. Third, there is a lending boom before the crisis. Finally, currency collapses that coincide with banking crises are typically associated with a rise in interest rates on domestic loans and a persistent decline in output. This paper attempts to provide an interpretation of why dual crises share these common elements.

To this end, we study the connection between government guarantees to foreign lenders, banks' hedging strategies and the aggregate level of economic activity. We consider two types of risk associated with exchange rate devaluations. The first type arises when banks borrow foreign currency, say dollars, and make loans denominated in units of the local currency. A second type arises when devaluations are associated with higher default rates on bank loans. This risk can exist even when banks make loans denominated in dollars. This is because these loans are often used to fund concerns that produce nontraded goods whose relative prices decline after a currency devaluation. ${ }^{2}$

In our model, absent government guarantees, it is optimal for banks to fully

\footnotetext{
${ }^{1}$ Kaminsky and Reinhart (1999) study empirically the link between banking and currency crises. See Diaz-Alejandro (1985) and Nyberg and Vihriälä (1993) for analyses of the 1982 Chilean and 1992 Finnish crises, respectively. Garber and Lall (1998) and Krueger and Tornell (1999) discuss the 1994 Mexican crisis.

${ }^{2}$ For example Gavin and Hausmann (1996) write that “... during the years leading up to the Chilean banking crisis (1982), banks were permitted to borrow in foreign currency but prohibited from taking the exchange risk, so that lending funded by international borrowing was required to be denominated in foreign currency. This was supposed to transfer the currency risk from banks to the nonfinancial firms to which banks made loans, but after the unexpected devaluation many firms found themselves unable to repay their loans in full or on time. Thus, the exchange rate risk that faced nonfinancial firms was to an extent borne by the banking systems in the form of credit risk."
} 
hedge exchange rate risk in forward markets. This is true regardless of which type of exchange rate risk banks face. However, the presence of government guarantees completely eliminates banks' incentives to hedge the risk of a devaluation. Indeed, it is optimal for banks to magnify their exchange rate exposure by selling dollars forward, so that they lose money when there is a devaluation. To the extent that banks are prevented from doing this, say by government regulation, our results provide a theory for why forward markets would not exist: in fixed exchange rate economies with government guarantees banks have no desire to buy dollars forward.

To study the macroeconomic effects of government guarantees we embed our model of banking into a general equilibrium environment which has two key features. First, firms in the output sector must borrow working capital from banks to pay labor. So from firms' perspective, the marginal cost of an extra unit of labor is the gross interest rate on bank loans times the real wage. ${ }^{3}$ Other things equal this means that a lower gross interest rate on domestic loans raises the demand for labor. Second, there is a fixed exogenous probability that the economy will permanently shift from a fixed exchange rate regime to one in which the exchange rate depreciates at a constant rate.

Prior to a devaluation, government guarantees to bank creditors lower the domestic interest rate and raise aggregate output, employment, real wages, the number of banks and the number of firms in the output sector. Thus the guarantees generate what appears to be a boom. But they also lead to a more fragile banking system. Banks do not hedge exchange rate risk. When a devaluation occurs, they renege on foreign debt and go bankrupt. At the same time, the devaluation leads to a permanent rise in the domestic interest rate and a permanent fall in aggregate output, employment, real wages, the number of banks, and the number of goods producing firms. Economies with and without government guarantees respond in the same way to a devaluation. But since an economy with

\footnotetext{
${ }^{3}$ In this respect our setup is similar to Christiano and Eichenbaum (1992) who emphasize the importance of the working capital channel in the monetary transmission mechanism.
} 
guarantees has a lower interest rate and a higher level of output to begin with, a devaluation leads to a relatively large rise in the interest rate and a relatively large fall in economic activity.

Given the central role that government guarantees play in our model, it is useful to provide intuition for how they affect the optimal hedging strategies of banks. The government guarantees that foreign creditors will receive $R^{*}$, the world gross risk-free interest rate, in the event that there is a devaluation and banks default on their debt. Suppose a bank contemplates hedging foreign excilange rate risk via forward contracts. The profits which are realized from these contracts in devaluation/bankruptcy states are seized by the government, so the banks assign zero value to them. But these contracts generate losses when there is no devaluation and the bank does not go bankrupt. It follows that banks have no incentive to buy forward contracts that generate positive payoffs when there is a devaluation.

The previous analysis implies that banks will not be perfectly hedged, and that they will go bankrupt when a devaluation occurs. To the extent that they have any assets in that state of the world, a portion of their value will be dissipated in bankruptcy proceedings. Hence banks ought to minimize their asset holdings in bankruptcy states of the world. A simple strategy for doing this is to sell dollars forward, which generates profits in the no devaluation state and losses in the devaluation state. Evidently in the presence of government guarantees it is optimal for banks to engage in hedging strategies that might be naively characterized as reckless speculation.

Our paper is organized as follows. In Section 2 we provide empirical motivation for our analysis. Section 3 lays out a competitive banking model. The key features of this model are that there is free entry and exit, and industry wide demand for loans is a decreasing function of the interest rate. Banks face exchange rate risk which they have an incentive to hedge because of bankruptcy costs. Section 4 studies banks' decisions to hedge exchange rate risk in a setting where the level of loans is predetermined with respect to the hedging decision. We study economies 
with and without government guarantees to bank creditors. In Section 5 we characterize the equilibrium of the banking industry when lending and hedging decisions are made simultaneously. Section 6 discusses the effects of introducing capital requirements and government guarantees that are not contingent on a devaluation. In Section 7 we study a version of the model where banks lend to domestic firms in dollars but face uncertainty with respect to loan repayment rates in the event of a devaluation. In Section 8 we embed our bcisking model in a general equilibrium environment and study the macroeconomic effects of government guarantees and devaluations. Section 9 contains concluding remarks.

\section{Empirical Motivation}

In the introduction we noted that there are important common elements in episodes where banking crises are associated with currency crises. Three of these elements have been extensively documented in the literature: (i) there are implicit government guarantees to domestic and foreign bank creditors prior to the currency crises; ${ }^{45}$ (ii) there is a rise in domestic interest rates and a fall in aggregate economic activity after a currency collapse; ${ }^{6}$ (iii) the crisis is preceeded by a lending boom. ${ }^{7}$

The final common element in banking/currency crises is that firms and financial intermediaries borrow extensively from abroad but do not completely hedge

\footnotetext{
${ }^{4}$ Indeed Mishkin (1996) and Obstfeld (1998) argue that in many cases a government's promise to maintain the exchange rate fixed is seen as providing an implicit government guarantee to bank depositors and foreign lenders against a possible devaluation.

${ }^{5}$ See the references in the introduction. In addition, see IMF (1998, page 35) and IMF (1999, page 21) for a discussion of guarantees in Thailand, Malaysia, Indonesia and Korea as well as Delhaise (1998). IMF (1998, page 39) details the extent to which implicit guarantees became explicit after the crises occurred. Drees and Pazarbaşioğlu (1998) discuss government guarantees in the Nordic country banking crises, while Calomiris (1998) discusses foreign bank creditor bail outs after the 1994 Mexican currency crises.

${ }^{6}$ See for example the IMF World Economic Outlook and International Capital Markets (various years).

${ }^{7}$ See Kaminsky and Reinhart (1999), Gavin and Hausmann (1996), and Drees, Burkhard and Pazarbaşioğlu: (1998).
} 
exchange rate risk. Unfortunately, due to data limitations, there is little formal empirical work measuring exchange rate exposure. One way to assess the potential magnitude of this exposure is to consider banks', firms' and financial intermediaries' net foreign assets prior to the onset of a crisis. There are two sources of data for doing this: the Bank of International Settlements (BIS) and the International Financial Statistics (IFS). An important advantage of the BIS data is that it is based on reports from major OECD banks. To the extent that accounting standards for banks in OECD countries are more standardized and carefully enforced than in non-OECD countries, the BIS data may be more reliable than the IFS data. This is because the latter are based, in part, on reports from agents in non-OECD countries who are borrowing funds. In addition, there are subtle ambiguities about how a given transaction might be reported in the IFS data. Suppose for example that Bank A in Country X borrows dollars from abroad and uses the proceeds to make dollar denominated loans to local firms. Bank A may take the position that this transaction does not cause a decline in its net foreign assets and would not report it as such. However, the transaction does expose the bank to the second type of exchange rate risk discussed in the introduction, namely the increase in loan default rates that often occurs after a devaluation. Since the BIS data are based on reports from the foreign creditors of Bank A (assuming that they are banks in OECD countries) the transaction would show up as a decrease in the net foreign assets of banks in Country X.

The advantage of the IFS data is that they are more comprehensive in coverage. The BIS data are based solely on reports from banks that are part of its system, so that if Bank A borrowed money from a foreign corporation or a non-BIS bank, the transaction would not be reflected in the BIS data. With these limitations in mind, we now report results based on both the BIS and IFS data.

Table 1 presents data on the net foreign assets of banks and firms based on BIS data, and the net foreign assets of deposit money banks (DMB) and other financial intermediaries (OFI) based on IFS data. We do this for various countries prior to the onset of currency/banking crises. A number of interesting features 
emerge from the table. First, in all cases, firms and banks in these countries had significant net foreign debt at the time of their crises. For the Nordic countries, the IFS data indicate a much larger net negative position than the BIS data. This may reflect that deposit money banks in the Nordic countries were borrowing substantial amounts of funds from entities other than BIS banks. For the East Asian countries we find that the BIS data indicate a much larger negative net position than the IFS data. This may reflect accounting problems with the data reported to the IFS by these countries.

The table pertains to levels of net foreign assets immediately prior to the crises. In most cases, these levels were achieved as the result of significant declines of net financial asset holdings in the preceding years. For example, in discussing Asia crises countries, Jackson (1999) writes: “... banks in each country rapidly increased their net foreign liabilities by large percentages during the four years prior to the crisis." The IMF World Economic Outlook and International Capital Markets (various years) document similar behavior in other crisis countries.

While highly suggestive, Table 1 can only establish that financial institutions had large exchange rate exposure in their loan portfolios. However, this exposure could, in principle, have been hedged. Given data limitations, it is not possible to precisely measure the extent to which large net foreign asset positions were hedged in the different crisis countries. Still, many qualitative analyses suggest that they were unhedged. For example, IMF (1999, p. 17) concludes that Indonesia, Korea and Thailand had "large unhedged private short-term foreign currency debt in a setting where corporations were highly geared; in Korea and Thailand, this debt was mainly intermediated through the banking system, while in Indonesia the corporations had heavier direct exposures to such debt." Folkerts-Landau et al. 
Table 1

Summary Indicators of Net Foreign Assets

(percent of GDP)

\begin{tabular}{|c|c|c|c|c|}
\hline \multirow[t]{2}{*}{ Source: ${ }^{8}$} & \multicolumn{2}{|c|}{ BIS } & \multicolumn{2}{|c|}{ IFS } \\
\hline & Banks & Firms & DMB & OFI \\
\hline Nordic Countries (1992) & & & & \\
\hline Finland & -8.5 & -8.1 & -23.2 & $\mathrm{n} / \mathrm{a}$ \\
\hline Norway & -5.5 & -6.1 & -11.7 & -0.9 \\
\hline Sweden & -18.4 & -6.2 & -27.0 & 0.3 \\
\hline Mexico (1994) & -3.8 & -8.6 & -1.2 & -7.5 \\
\hline East Asia (1997) & & & & \\
\hline Indonesia & -6.9 & -16.1 & -1.7 & $\mathrm{n} / \mathrm{a}$ \\
\hline Korea & -12.8 & -5.2 & -2.2 & -3.2 \\
\hline Malaysia & -11.5 & -4.4 & -7.0 & 0.1 \\
\hline Philippines & -8.5 & -2.1 & -7.5 & $\mathrm{n} / \mathrm{a}$ \\
\hline Thailand & -48.9 & -7.0 & -22.8 & -2.7 \\
\hline
\end{tabular}

(1997, p. 46) write, with reference to Thailand, "While banks are believed to have hedged most of their net foreign liabilities, the opposite is believed to be true for the corporate sector. The combination of a stable exchange rate and a wide differential between foreign and (much higher) domestic interest rates provided a strong incentive for firms to take on foreign currency liabilities. ... Hence, in addition to their own foreign exchange exposure, banks may have a large indirect exposure in the form of credit risk to firms that have borrowed in foreign currencies." 9

\footnotetext{
${ }^{8}$ BIS measures of NFA are end-of-quarter. For the Nordic countries, 1991Q3, for Mexico, 1994Q3, for East Asia, 1997Q2. The IFS measures of NFA are end-of-year. For the Nordic countries, 1990, for Mexico, 1993, for East Asia 1996. DMB: Deposit Money Banks. OFI: Other Financial Institutions.

${ }^{9}$ See also Eichengreen and Fishlow (1998).
} 


\section{A Model of Banking in an Small Open Economy}

We begin our theoretical analysis by studying a partial equilibrium model of banks in a small open economy. By assumption there is a single consumption good and no barriers to trade, so that purchasing power parity holds:

$$
P_{t}=S_{t} P_{t}^{*}
$$

Here $P_{t}$ and $P_{t}^{*}$ denote the domestic and foreign price level respectively, while $S_{t}$ denotes the exchange rate defined as units of domestic currency per unit of foreign currency. For convenience we normalize the foreign price level to one: $P_{t}^{*}=1$ for all $t$.

We assume that the exchange rate regime, $e_{t}$, follows a Markov chain. The economy is initially in a fixed exchange rate regime, $e_{t}=1$, with exchange rate $S_{t}=s_{1}$. The economy can switch to a devaluation regime, $e_{t}=2$, which is an absorbing state. The probability transition matrix is given by:

$$
T=\left[\begin{array}{cc}
1-p & p \\
0 & 1
\end{array}\right]
$$

where $p=\operatorname{Pr}\left(e_{t}=2 \mid e_{t}=1\right)$, is the probability of switching from the fixed exchange rate regime to the devaluation regime.

When the exchange rate is devalued the exchange rate depreciates to some value $s_{2}=\gamma s_{1}, \gamma>1$, and then follows a crawling peg in which the currency continues to depreciate at the rate $\gamma \cdot{ }^{10}$ To summarize, the exchange rate, $S_{t}$, is given by:

$$
S_{t}= \begin{cases}s_{1} & \text { if } e_{t}=1 \\ \gamma s_{1} & \text { if } e_{t}=2 \text { and } e_{t-1}=1 \\ \gamma S_{t-1} & \text { if } e_{t}=e_{t-1}=2\end{cases}
$$

\footnotetext{
${ }^{10}$ The analysis can be generalized to the case where there is more than one possible value of $s$ in the event of a devaluation. To preserve the possibility of full hedging would require more complex hedging strategies than the ones considered here. In particular we would require an exotic security with payoffs $a+b / S$ in the devaluation state.
} 
Since we focus on banks' hedging strategies prior to the devaluation, we suppress time subscripts throughout much of the rest of the paper.

\subsection{The Banking Sector}

To be in the banking business requires an investment of $K$ units of output at the beginning of every period. If the bank does not exit the industry by the end of the period it recoups $(1-\delta) K$ units of its capital investment. Here $\delta$ represents the rate of depreciation on capital. If the bank does exit, it cannot retrieve any of its initial capital investment. Since capital can be invested in world capital markets, the per period opportunity cost of entering the banking industry is $R^{*} K$. Here $R^{*}$ is the gross interest rate on foreign currency, i.e. dollar-denominated loans in the world capital market. ${ }^{11}$

To make our argument as simply as possible we abstract from the role of banks as producers of information and focus directly on the real costs of making loans. ${ }^{12}$ By assumption, the real cost of lending $L$ units of output is $\psi(L)$. The function $\psi(L)$ is positive, twice continuously differentiable and convex, so that the marginal cost of making loans is increasing.

Throughout we assume that banks are perfectly competitive. As discussed in the introduction, evidence from recent currency crises indicates that banks are exposed to different types of exchange rate risk. In this section we concentrate on the risk that arises when banks borrow foreign currency at a gross interest rate $R^{b}$, while issuing non-indexed loans to domestic firms that are to be repaid in local currency units at a gross interest rate $R^{a}$. To simplify the analysis we abstract from the possibility that banks borrow funds from domestic residents. Instead we assume that banks finance themselves entirely by borrowing $L$ dollars

\footnotetext{
${ }^{11}$ It would be straightforward to extend our analysis to allow for long lived banks. In particular, our results would continue to hold if banks had to pay a sunk cost to enter the industry, provided that the devaluation is large enough to generate exit.

${ }^{12}$ For a similar model see Chari, Christiano an Eichenbaum (1996) and Edwards and Vegh (1997). For alternative models of the role of banks in currency crises see, for example, Akerlof and Romer (1993), Caballero and Krishnamurthy (1998) and Chang and Velasco (1999).
} 
in the international capital market. These funds are converted into units of local currency at the exchange rate $S$. Banks can hedge exchange rate risk by entering into forward contracts. ${ }^{13}$ Let $F$ denote the one-period forward exchange rate defined as units of local currency per dollar. By assumption these contracts are priced in a risk neutral manner, so that:

$$
\frac{1}{F}=(1-p) \frac{1}{s_{1}}+p \frac{1}{s_{2}}
$$

Dollar-denominated profits, $\pi$, inclusive of end-of-period capital, can be written as a function of the exchange rate and the borrowing rate:

$$
\pi\left(S, R^{b}\right)=\frac{R^{a} s_{1} L}{S}-R^{b} L-\psi(L)+(1-\delta) K+x\left(\frac{1}{F}-\frac{1}{S}\right) .
$$

Here $x$ denotes the number of units of local currency sold by the bank in the forward market.

Banks can default on loans contracted in the international capital market. It is optimal for banks to default in states of the world where $\pi$ is negative. The cost of default is $\omega+\lambda\left[R^{a} s_{1} L / S-\psi(L)+(1-\delta) K+x(1 / F-1 / S)\right]$. Here $\omega$ represents fixed costs associated with bankruptcy and $\lambda$ represents the fraction of the remaining gross assets of the bank that are dissipated upon default. ${ }^{14}$ Assets net of bankruptcy costs, $(1-\lambda)\left[R^{a} s_{1} L / S-\psi(L)+(1-\delta) K+x(1 / F-1 / S)\right]-\omega$, are distributed to the bank's international creditors. Here we have assumed that forward contracts must be settled before the bank's foreign creditors are paid.

The expected profit of a bank that defaults whenever $\pi\left(S, R^{b}\right)<0$ is

$$
V=(1-p) \max \left\{\pi\left(s_{1}, R^{b}\right), 0\right\}+p \max \left\{\pi\left(s_{2}, R^{b}\right), 0\right\} .
$$

In the absence of loan guarantees, $R^{b}$ is determined by the condition that the expected return to international creditors equals $R^{*}$.

\footnotetext{
${ }^{13}$ See Albuquerque (1999) for a general discussion of optimal hedging strategies, including the choice between forwards and options as hedging instruments.

${ }^{14} \mathrm{As}$ will be clear from our analysis below, when $\omega$ is zero agents are indifferent between various hedging strategies. A positive $\omega$ serves the role of a 'tie breaker'.
} 
If $\pi\left(s_{1}, R^{b}\right)<0$ and $\pi\left(s_{2}, R^{b}\right)>0$, then

$$
R^{*} L=p R^{b} L+(1-p)\left\{(1-\lambda)\left[R^{a} L-\psi(L)+(1-\delta) K+x\left(\frac{1}{F}-\frac{1}{s_{1}}\right)\right]-\omega\right\}
$$

If $\pi\left(s_{1}, R^{b}\right)>0$ and $\pi\left(s_{2}, R^{b}\right)<0$, then

$$
R^{*} L=(1-p) R^{b} L+p\left\{(1-\lambda)\left[R^{a} \frac{s_{1}}{s_{2}} L-\psi(L)+(1-\delta) K+x\left(\frac{1}{F}-\frac{1}{s_{2}}\right)\right]-\omega\right\} \text {. }
$$

Equation (3.6) applies to the case where banks default when $S=s_{1}$, while equation (3.7) applies to the case where banks default when $S=s_{2}$. If profits are positive in both states of the world, the bank is fully hedged, and $R^{b}=R^{*}$. Implicit in these conditions is the assumption that bank loans and forward operations are publicly observable.

Consider an economy with government guarantees that apply only to the devaluation state. Then $R^{b}$ is still determined by (3.6) when $\pi\left(s_{1}, R^{b}\right)<0$ and $\pi\left(s_{2}, R^{b}\right)>0$, so that since default occurs when $S=s_{1}$. However, if $\pi\left(s_{1}, R^{b}\right)>0$ and $\pi\left(s_{2}, R^{b}\right)<0$, then default occurs when $S=s_{2}$, and the government ensures that foreign creditors get paid in full. ${ }^{15}$ It follows that in the presence of guarantees, foreigners are willing to make loans to a domestic bank at the rate $R^{b}=R^{*}$, as long as the bank pursues a loan/hedge policy that is consistent with default occurring only when the exchange rate is devalued.

Finally, regardless of whether there are government guarantees, we assume that banks choose $x$ and $L$ subject to the constraint that forward contracts can be honored in all states of the world. This implies that

$$
\text { if } \pi\left(s_{i}, R^{b}\right)<0 \text { then }(1-\lambda)\left[R^{a} \frac{s_{1}}{s_{i}} L-\psi(L)+(1-\delta) K+x\left(\frac{1}{F}-\frac{1}{s_{i}}\right)\right] \geq \omega
$$

so that the bank's residual value net of bankruptcy costs is nonnegative after the settlement of forward contracts whether or not the currency is devalued. We

\footnotetext{
${ }^{15}$ As discussed by Merton (1987) in the context of deposit insurance, these guarantees can be interpreted as a free put option provided by the government to banks.
} 
will refer to (3.8) as the 'no default on forward contracts' condition. Note that this constraint does not apply to fully hedged banks (where both $\pi\left(s_{1}, R^{b}\right)$ and $\pi\left(s_{2}, R^{b}\right)$ are positive), since for those financial institutions default is not an issue.

The objective function of the representative bank (3.5) can always be rewritten as:

$$
V=\frac{R^{a} s_{1}}{F} L-\psi(L)+(1-\delta) K-E C B(x, L),
$$

where $E C B(x, L)$ is the expected cost of borrowing. To see this consider a bank for whom it is optimal to default when $S=S_{2}$. Its expected profit is given by:

$$
V=(1-p)\left[\frac{S_{1} R^{a}}{S_{1}} L-R^{b} L-\psi(L)+(1-\delta) K+x\left(\frac{1}{F}-\frac{1}{S_{1}}\right)\right] .
$$

Adding and subtracting $p\left[\frac{S_{1} R^{a}}{S_{2}} L-\psi(L)+(1-\delta) K\right]+p x\left(1 / F-1 / S_{2}\right)$, combining the terms that multiply $R^{a} L$, and using the fact that expected profits on forward contracts are zero we obtain equation (3.9).

In general $E C B(x, L)$ is the probability of not defaulting times $R^{b} L$ plus the probability of defaulting times the residual assets of the bank. For example, in the case of a bank with a hedging strategy such that it is optimal to default when $S=s_{2}$ the expected cost of borrowing is given by:

$$
E C B(x, L)=(1-p) R^{b} L+p\left[\frac{s_{1}}{s_{2}} R^{a} L-\psi(L)+(1-\delta) K+x\left(\frac{1}{F}-\frac{1}{s_{2}}\right)\right]
$$

When the bank does not default, which occurs with probability $(1-p)$, it repays $R^{b} L$ to foreign creditors. If it defaults, the bank hands over $\left(s_{1} / s_{2}\right) R^{a} L-\psi(L)+$ $(1-\delta) K+x\left(1 / F-1 / s_{2}\right)$ to its creditors. But because of bankruptcy costs the creditors receive less than this. They only receive what is left over after the bankruptcy costs are incurred: $(1-\lambda)\left[\left(s_{1} / s_{2}\right) R^{a} L-\psi(L)+(1-\delta) K+x(1 / F-\right.$ $\left.\left.1 / s_{2}\right)\right]-\omega$.

Throughout the paper we will see that it is possible to gather intuition about the optimal bank hedging strategy by deriving the value of $x$ that minimizes the expected cost of borrowing, $\operatorname{ECB}(x, L)$, for a given loan size $L$. 


\section{Optimal Bank Hedging when Loans are Pre-determined}

To hone our intuition about the effects of government guarantees it is useful to start by considering the case where the amount of real lending, $L$, is exogenously fixed. Given this assumption, a bank's only decision is how much exchange rate risk to hedge. In this section we prove two propositions: (i) it is optimal for a bank to fully hedge exchange rate risk when there are no government guarantees; and (ii) it is not optimal for a bank to hedge exchange rate risk in the presence of government guarantees. These propositions mirror the classic results in Kareken and Wallace (1978) on the impact of deposit insurance on banks' optimal portfolio decisions. While the nature of government guarantees are different in the two analyses, both our results and those of Kareken and Wallace (1978) are driven by: (i) the presence of bankruptcy costs, and (ii) the ability of banks to make portfolio decisions that minimize the value of their assets in bankruptcy states.

To state our results formally it is useful to define $\pi^{L}\left(S, R^{b}\right)$, the profits from lending:

$$
\pi^{L}\left(S, R^{b}\right)=\frac{R^{a} s_{1} L}{S}-R^{b} L-\psi(L)+(1-\delta) K .
$$

Total bank profits from both lending and hedging activities can be written as:

$$
\pi\left(S, R^{b}\right)=\pi^{L}\left(S, R^{b}\right)+x\left(\frac{1}{F}-\frac{1}{S}\right)
$$

Proposition 4.1. In an economy with no government guarantees, $L$ fixed and (3.8) satisfied, complete hedging is optimal for $0<\lambda<1$. When $\lambda=\omega=0$ the Modigliani-Miller theorem applies and the bank is indifferent between hedging and not hedging.

Proof: Expected profit for a fully hedged bank is given by

$$
\begin{aligned}
V^{H} & =(1-p) \max \left\{\pi\left(s_{1}, R^{*}\right), 0\right\}+p \max \left\{\pi\left(s_{2}, R^{*}\right), 0\right\} \\
& =(1-p) \pi\left(s_{1}, R^{*}\right)+p \pi\left(s_{2}, R^{*}\right) \\
& =(1-p) \pi^{L}\left(s_{1}, R^{*}\right)+p \pi^{L}\left(s_{2}, R^{*}\right) .
\end{aligned}
$$


where the second line follows from the fact that total profits are positive in both states of the world for a fully-hedged bank. The third line results from the riskneutral pricing of forward contracts, which implies that the expected value of the bank's forward position is zero.

The expected profit of a bank that chooses not to be fully hedged and to go bankrupt when $S=s_{2}$ is given by

$$
\begin{aligned}
V^{I} & =(1-p) \pi\left(s_{1}, R^{b}\right) \\
& =(1-p)\left[\pi^{L}\left(s_{1}, R^{b}\right)+x\left(\frac{1}{F}-\frac{1}{s_{1}}\right)\right] \\
& =(1-p)\left[\pi^{L}\left(s_{1}, R^{*}\right)+R^{*} L-R^{b} L+x\left(\frac{1}{F}-\frac{1}{s_{1}}\right)\right] .
\end{aligned}
$$

The equation that determines the borrowing rate for this bank implies

$$
(1-p) R^{b} L=R^{*} L-p(1-\lambda)\left[\pi^{L}\left(s_{2}, R^{*}\right)+R^{*} L+x\left(\frac{1}{F}-\frac{1}{s_{2}}\right)\right]+p \omega .
$$

Hence

$$
\frac{\partial V^{I}}{\partial x}=(1-p)\left(\frac{1}{F}-\frac{1}{s_{1}}\right)+p(1-\lambda)\left(\frac{1}{F}-\frac{1}{s_{2}}\right)=-\lambda p\left(\frac{1}{F}-\frac{1}{s_{2}}\right)<0 .
$$

Therefore, the bank will choose the lowest value of $x$ consistent with the no default on forward contracts condition, (3.8):

$$
x=\left(\frac{1}{F}-\frac{1}{s_{2}}\right)^{-1}\left[\frac{\omega}{1-\lambda}-\pi^{L}\left(s_{2}, R^{*}\right)-R^{*} L\right] .
$$

This value of $x$ reduces the residual value of the bank to zero and implies that the borrowing rate is $R^{b}=R^{*} /(1-p)$. Using these two facts in (4.2) we obtain

$$
V^{I}=V^{H}-p \frac{\omega}{1-\lambda}
$$

This implies that full hedging dominates any strategy consistent with default in the devaluation state. 
To complete the proof we need to show that full hedging also dominates any strategy in which the bank defaults in the no-devaluation state. A similar argument to the one above can be used to show that the best strategy of this type involves setting $x$ to the maximal value consistent with the no default on forward contracts condition, (3.8). Expected profit evaluated at this value of $x$, which we denote by $V^{I I}$, is given by

$$
V^{I I}=V^{H}-(1-p) \frac{\omega}{1-\lambda}
$$

Thus, the best strategy that involves default in the no devaluation state is dominated by full hedging.

If $\omega=0, V^{H}=V^{I}=V^{I I}$. If, in addition, $\lambda=0$ then the Modigliani-Miller theorem applies to any feasible hedging strategy.

The basic intuition for this result is straightforward. The expected cost of borrowing for a hedged bank is $R^{*} L$. For a bank that defaults in the devaluation state the expected cost of borrowing is given by (3.10), while its borrowing rate, $R^{b}$, is given by (3.7). Using these two equations it can be shown that the bank's expected cost of borrowing is minimized if it leaves just enough residual value when $S=s_{2}$ to allow its foreign creditors to pay the fixed cost of bankruptcy. Thus it sets $x$ such that:

$$
\frac{s_{1}}{s_{2}} R^{a} L-\psi(L)+(1-\delta) K+x\left(\frac{1}{F}-\frac{1}{s_{2}}\right)=\frac{\omega}{1-\lambda} .
$$

In this case, the bank's borrowing rate will be $R^{b}=R^{*} /(1-p)$, and its expected cost of borrowing will be $R^{*} L+p \omega /(1-\lambda)$. Similarly it can be shown that the minimum expected cost of borrowing for a bank that defaults when $S=s_{1}$ is $E C B=R^{*} L+(1-p) \omega /(1-\lambda)$. In both cases, when $\omega$ is strictly positive, the expected cost of borrowing is greater than $R^{*}$ for a bank that is not hedged and equal to $R^{*}$ for a fully hedged bank.

Proposition 4.2. Consider an economy with government guarantees and $L$ fixed. Suppose that: $0<\lambda<1,0<\omega<(11-\lambda) R^{*} L$ and equation (3.8) is satisfied. 
Then full hedging is not optimal and the optimal strategy is to set $x$ to its lowest permissible bound.

Proof: If the bank is not fully hedged, and defaults when $S=s_{2}$, its expected profit is given by $(1-p)\left[\pi^{L}\left(s_{1}, R^{*}\right)+x\left(1 / F-1 / s_{1}\right)\right]$. This expression is strictly decreasing in $x$. So it is optimal for such a bank to set $x$ to its lowest permissible value. It follows that the maximal profits of a nonhedged bank are equal to $V^{I}=V^{H}+p\left[R^{*} L-\omega /(1-\lambda)\right]>V^{H}$. Here $V^{H}$, given by (4.1), denotes the expected profits of a fully hedged bank. Finally, to show that it is not optimal to choose a hedging strategy consistent with default in the no devaluation state, note that government guarantees do not apply in this state. Consequently, expected profit is given by (4.3), so that this strategy is dominated by full hedging.

To obtain intuition for this result, note that the expected cost of borrowing for a fully hedged bank is $R^{*} L$. If the bank is not fully hedged and there are government guarantees the expected cost of borrowing is:

$$
E C B=(1-p) R^{*} L+p\left[\frac{R^{a}}{s_{2}} s_{1} L-\psi(L)+(1-\delta) K+r\left(\frac{1}{F}-\frac{1}{s_{2}}\right)\right] .
$$

By setting $x$ to the lowest permissible value consistent with the no default on forward contracts condition, (3.8) this cost is reduced to $(1-p) R^{*} L+p w /(1-$ $\lambda$ ), which is lower than $R^{*} L$ under our assumption that the fixed cost of bankruptcy, $\omega$, is strictly positive but smaller than $(1-\lambda) R^{*} L$.

Note that with government guarantees, banks that aren't fully hedged go bankrupt in the devaluation state. Since the lowest permissible value of $x$ is negative, they adopt a hedging strategy that involves selling dollars forward. While this might be characterized as reckless speculation, it is simply the optimal response of banks to government guarantees when there are bankruptcy costs.

We conclude this section by asking the question: would banks prefer to make dollar-denominated loans? The answer is no. It is straightforward to show that without government guarantees banks with dollar-denominating loans will not choose to go bankrupt. As a result, their expected cost of borrowing will be $R^{*} L$, 
regardless of whether they make their loans in dollars or not. Under guarantees, banks are also indifferent between making dollar denominated loans and nonindexed loans in local currency. We can show that banks that denominate their loans in dollars choose to go bankrupt when there is a devaluation. Their optimal hedging strategy will involve a more negative value of $x$, so as to ensure that the residual value of their assets in the devaluation state will equal zero. Given this strategy their expected cost of borrowing continues to be $(1-p) R^{*} L+p \omega /(1-\lambda)$.

\section{Equilibrium in the Banking Industry}

In this section we characterize the equilibrium of the banking industry assuming an exogenous demand schedule for bank loans. Our objective here is to study the impact of government guarantees on the hedging behavior of the banking industry. As it turns out doing so is substantially more complex than the task confronted in the previous section. This is because banks must choose how many loans to produce at the same time as their hedging strategy.

Suppose that the total demand for bank loans is given by the function $D\left(R^{a}\right)$ which is assumed to be nonnegative and nonincreasing in $R^{a}$. Consider the equilibrium of the banking industry with no government guarantees. The representative bank's problem is to choose $(x, L)$ to maximize $V$, given by (3.5), subject to (3.6), (3.7), and (3.8).

Definition. An equilibrium for the banking industry is a value for $R^{a}$, a schedule, $R^{b}(x, L)$, a level of hedging, $x$, a level of lending $L$, and a number of banks $B$ such that when banks take $R^{a}$ and the schedule $R^{b}(x, L)$ as given, (i) the pair $(x, L)$, maximizes the bank's expected profit, (ii) the bank's expected profit is $R^{*} K$, and (iii) the market for bank loans clears, $L B=D\left(R^{a}\right)$.

We now characterize the equilibrium of an economy with no government guarantees.

Proposition 5.1. Suppose that $(1-\delta) K-\psi(0)>0$. The equilibrium of an economy with no government guarantees is unique and has the following properties. 
First, the equilibrium level of lending, $L_{n}$, is given by the unique solution to

$$
\psi^{\prime}\left(L_{n}\right) L_{n}-\psi\left(L_{n}\right)+(1-\delta) K=R^{*} K .
$$

Second, the equilibrium value of $R^{a}$ is

$$
R_{n}^{a}=\frac{F}{s_{1}}\left[R^{*}+\psi^{\prime}\left(L_{n}\right)\right] .
$$

Third, the equilibrium level of hedging is any $x_{n}$, such that $\underline{X} \leq x_{n} \leq \bar{X}$, where

$$
\underline{X}=F\left[R^{*}+\psi^{\prime}\left(L_{n}\right)\right] L_{n}-\frac{R^{*} K}{\frac{1}{F}-\frac{1}{s_{2}}}
$$

and

$$
\bar{X}=F\left[R^{*}+\psi^{\prime}\left(L_{n}\right)\right] L_{n}+\frac{R^{*} K}{\frac{1}{s_{1}}-\frac{1}{F}} .
$$

Fourth, the equilibrium value of $R^{b}=R^{*}$.

Here we sketch the proof of the previous proposition, and refer the reader to the Appendix for a formal proof. The no default on forward contracts condition, (3.8), defines the set $\Omega$ of combinations $(x, L)$ that are permissible. Constraints (3.6) and (3.7) make it convenient to partition $\Omega$ into four disjoint subsets: (i) $\Omega_{1}$ is the set of points in which $\pi\left(s_{i}, R^{*}\right) \geq 0$ for $i=1,2$, (ii) $\Omega_{2}$ is the set of points in which $\pi\left(s_{1}, R^{b}\right) \geq 0, \pi\left(s_{2}, R^{b}\right)<0$ and $R^{b}$ is given by (3.7), (iii) $\Omega_{3}$ is the set of points in which $\pi\left(s_{1}, R^{b}\right)<0, \pi\left(s_{2}, R^{b}\right) \geq 0$, and $R^{b}$ is given by (3.6), and (iv) $\Omega_{4}$ is $\Omega-\Omega_{1} \cup \Omega_{2} \cup \Omega_{3}$. The condition $(1-\delta) K-\psi(0)>0$ is used to guarantee that there exist $(x, L) \in \Omega_{1}$ with $L>0$.

Given a value for $R^{a}$, the expected profit of a bank with $(x, L) \in \Omega_{1}$ is given by

$$
V_{1}=\frac{s_{1}}{F} R^{a} L-R^{*} L+(1-\delta) K-\psi(L) .
$$

For $(x, L) \in \Omega_{2}$, the expected profit of a bank is given by

$$
V_{2}=(1-p)\left[R^{a} L-R^{b} L+(1-\delta) K-\psi(L)+x\left(\frac{1}{F}-\frac{1}{s_{1}}\right)\right] .
$$


Using (3.7) to replace $R^{b}$ in the previous expression, we can show that $V_{2}$ is strictly decreasing in $x$. Thus for an arbitrary value of $L, V_{2}$ is maximized when $x$ equals the lowest value consistent with the no default on forward contracts condition, (3.8). Setting $x$ to its optimal value we can write $V_{2}$ as

$$
V_{2}=\frac{s_{1}}{F} R^{a} L-R^{*} L+(1-\delta) K-\psi(L)-p \frac{\omega}{1-\lambda}
$$

For $(x, L) \in \Omega_{3}$, the expected profit of a bank is given by

$$
V_{3}=p\left[R^{a} \frac{s_{1}}{s_{2}} L-R^{b} L+(1-\delta) K-\psi(L)+x\left(\frac{1}{F}-\frac{1}{s_{2}}\right)\right] .
$$

Using (3.6) to replace $R^{b}$ in the previous expression, we can show that $V_{3}$ is strictly increasing in $x$. Thus for an arbitrary value of $L, V_{3}$ is maximized when $x$ equals the highest value consistent with the no default on forward contracts condition, (3.8). Setting $x$ to its optimal value we can write $V_{3}$ as

$$
V_{3}=\frac{s_{1}}{F} R^{a} L-R^{*} L+(1-\delta) K-\psi(L)-(1-p) \frac{\omega}{1-\lambda} .
$$

Note that for any given $L, V_{i}<V_{1}, i=2,3$. In the Appendix we establish that the set of admissible values of $L$ in $\Omega_{1}$ contains the sets of admissible values of $L$ in $\Omega_{2}$ and $\Omega_{3}$ for any $R^{a}$. Taken together these results imply that it is not optimal for a bank to choose $(x, L) \in \Omega_{i}, i=2,3$. Finally note that for $(x, L) \in \Omega_{4}, \pi\left(S, R^{b}\right)$ is negative in both states of the world and the expected profit of a bank is $V_{4}=0$. Note that for $L=0, V_{1}=(1-\delta) K-\psi(0)>0$. So it can never be optimal to choose $(x, L)$ in $\Omega_{4}$.

We now characterize the optimal $(x, L)$ in $\Omega_{1}$. The bank's first order condition for $L$ is given by

$$
R^{a}=\frac{F}{s_{1}}\left[R^{*}+\psi^{\prime}(L)\right]
$$

Replacing $R^{a}$ in $V_{1}$ with this expression we find that the maximal value of $V_{1}$ is $\psi^{\prime}(L) L-\psi(L)+(1-\delta) K$. Free entry implies that equilibrium profits equal $R^{*} K$. Hence (5.1) and (5.2) jointly characterize the equilibrium values of $R^{a}$ and 
$L$. Note that for $x$ to be consistent with full hedging, $x$ must lie between $\underline{X}$ and $\bar{X}$. Finally, the number of banks, $B$, is determined by $B=D\left(R^{a}\right) / L$.

We now characterize the equilibrium of an economy with government guarantees.

Proposition 5.2. Suppose that $(1-\delta) K-\psi(0)>0$ and $\omega<(1-\lambda) R^{*} L_{n}$. The equilibrium of an economy with government guarantees is unique and has the following properties. First, the equilibrium level of lending, $L_{g}$, is the unique solution to

$$
\psi^{\prime}\left(L_{g}\right) L_{g}-\psi\left(L_{g}\right)+(1-\delta) K-p \frac{\omega}{1-\lambda}=R^{*} K
$$

Second, the equilibrium value of $R^{a}$ is

$$
R_{g}^{a}=\frac{F}{s_{1}}\left[(1-p) R^{*}+\psi^{\prime}\left(L_{g}\right)\right]
$$

Third, the equilibrium level of $x$ is the minimum permissible value consistent with (3.8) for $S=s_{2}$. Fourth, the equilibrium value of $R^{b}=R^{*}$.

Here we sketch the proof of the previous proposition. We refer the reader to the Appendix for a formal proof. As before it is convenient to partition $\Omega$ into four disjoint subsets. Sets $\Omega_{1}, \Omega_{3}$ and $\Omega_{4}$ are defined as before. We define $\Omega_{2}$ as the set of points in which $\pi\left(s_{1}, R^{*}\right) \geq 0, \pi\left(s_{2}, R^{*}\right)<0$. Note that for a given value of $R^{a}, V_{1}$ and $V_{3}$ are still given by (5.3) and (5.5). It also remains true that $V_{4}=0$. Proceeding as before, we can eliminate $(x, L)$ pairs in $\Omega_{3}$ and $\Omega_{4}$ as potential equilibria. The value of $V_{2}$ is now given by

$$
V_{2}=(1-p)\left[R^{a} L-R^{*} L+(1-\delta) K-\psi(L)+x\left(\frac{1}{F}-\frac{1}{s_{1}}\right)\right] .
$$

The difference relative to (5.4) is that the borrowing rate is now $R^{*}$. Clearly, $V_{2}$ is strictly decreasing in $x$. Thus for an arbitrary value of $L, V_{2}$ is maximized when $x$ equals the lowest value consistent with the no default on forward contracts 
condition, (3.8). The resulting value of $V_{2}$ is

$$
\begin{aligned}
V_{2} & =\frac{s_{1}}{F} R^{a} L-(1-p) R^{*} L+(1-\delta) K-\psi(L)-p \frac{\omega}{1-\lambda} \\
& =V_{1}+p\left(R^{*} L-\frac{\omega}{1-\lambda}\right) .
\end{aligned}
$$

Since we assumed that fixed bankruptcy costs are small enough that $\omega<(1-$ d) $R^{*} L_{n}$, we have that $V_{2}>V_{1}$ for all $L \geq L_{n}$. In a full hedging equilibrium $L=L_{n}$. Given this value of $L$ an individual bank could, by changing its hedging strategy, obtain an expected profit of $V_{2}>V_{1}$. Therefore a full hedging equilibrium does not exist.

The value of $L$ that maximizes $V_{2}$ is given by:

$$
\frac{s_{1}}{F} R^{a}=(1-p) R^{*}+\psi^{\prime}(L) .
$$

The maximal value of $V_{2}$ is given by $\psi^{\prime}(L) L-\psi(L)+(1-\delta) K-p \frac{\omega}{1-\lambda}$. In equilibrium the free entry condition ensures that $V_{2}=R^{*} K$. This in turn implies that if $\omega<(1-\lambda) R^{*} L_{n}$ the equilibrium level of lending is a value $L_{g}>L_{n}$ that satisfies equation (5.6). Finally, the number of banks is determined by $B=$ $D\left(R^{a}\right) / L$.

We will now compare the value of $R^{a}$ in economies with and without government guarantees.

Corollary 5.3. For sufficiently small $\omega$ the ask interest rate is lower in an economy with guarantees than in one without guarantees $\left(R_{g}^{a}<R_{n}^{a}\right)$.

Proof: Equations (5.2) and (5.7) imply that:

$$
R_{g}^{a}-R_{n}^{a}=\frac{F}{s_{1}}\left[-p R^{*}+\psi^{\prime}\left(L_{g}\right)-\psi^{\prime}\left(L_{n}\right)\right] .
$$

Equations (5.6) and (5.1) imply that $\lim _{\omega \rightarrow 0} L_{g}=L_{n}$. This implies that $\lim _{\omega \rightarrow 0}$ $R_{g}^{a}<R_{n}^{a}$ 


\section{Effects of Banking Regulation}

\subsection{Capital Requirements}

In the previous section we argued that government guarantees make the banking system more fragile: banks adopt loan/hedging strategies which make it optimal for them to go bankrupt after a devaluation. In some environments, imposing capital requirements on banks can reduce the probability of bankruptcy. This is not the case in our model, once we take into account banks' hedging strategies. Recall that banks must commit $K$ units of capital to operate, of which they retrieve $(1-\delta) K$ at the end of the period if they do not default. Suppose that the government imposes capital requirements of the following form. In the beginning of the period a bank must place $K^{\prime}$ units of capital with the government, which it retrieves if they do not default. If the bank defaults it forfeits the right to $K^{\prime}$. One can show this policy generates a rise in the amount that each individual bank lends and, in an economy with guarantees, a rise in $R^{a}$. This in turn implies that aggregate lending and the number of banks decline in response to the policy. ${ }^{16}$

It might be thought that these contractionary effects are worth bearing if capital requirements affected the probability of bank default. But they do not. There does exist a $K^{\prime}$ large enough that an unhedged bank $(x=0)$ would never choose to default. In this sense capital requirements can be seen as a substitute for hedging. But when banks are free to choose their own hedging position, they will undo the effects of capital requirements. In particular, in an economy with guarantees, banks will choose a lower value of $x$ such that the residual value of the bank (inclusive of $K^{\prime}$ ) will be zero in the devaluation state.

\footnotetext{
${ }^{16}$ These results are similar to those obtained by Kareken and Wallace (1978) who analyze the effect of imposing capital requirement on fractional reserve banks in the presence of deposit insurance.
} 


\subsection{Non-contingent Government Guarantees}

In this subsection we show that the response of the banking system to government guarantees depends sensitively on their design. In particular when guarantees apply to all states of the world, incentives are so distorted that banks may find it optimal to pursue loan/hedge strategies that lead them to default in the likely event that a devaluation does not occur. This is the case when devaluations occur with low probability. We summarize this result in the following proposition.

Proposition 6.1. Suppose that the government guarantees foreign loans for $S=$ $s_{1}$ and $S=s_{2}$. In addition assume that $p<1 / 2$ and $\omega<(1-\lambda) R^{*} L_{n}$. Then there is a unique equilibrium in which banks default when $S=s_{1}$. In addition, for sufficiently small $\omega$, the equilibrium ask rate, $R^{a}$ is lower than $R_{g}^{a}$

A formal proof of this proposition is contained in the Appendix. Here we describe the basic intuition behind the result. The expected cost of borrowing for a bank that defaults when a devaluation occurs is given by:

$$
E C B=(1-p) R^{*} L+p\left[\frac{s_{1}}{s_{2}} R^{a} L-\psi(L)+(1-\delta) K+x\left(\frac{1}{F}-\frac{1}{s_{2}}\right)\right] .
$$

This can be minimized by setting $x$ to the lowest value consistent with the no default on forward contracts condition, (3.8). The resulting minimal value of $\mathrm{ECB}$ is given by

$$
E C B=(1-p) R^{*} L+p \frac{\omega}{1-\lambda} .
$$

In contrast the expected cost of borrowing for a bank that defaults when a devaluation does not occur is given by:

$$
E C B=p R^{*} L+(1-p)\left[R^{a} L-\psi(L)+(1-\delta) K+x\left(\frac{1}{F}-\frac{1}{s_{1}}\right)\right] .
$$

This cost can be minimized by setting $x$ to the highest possible value consistent with the no default on forward contracts condition, (3.8). The resulting expected cost is: 


$$
E C B=p R^{*} L+(1-p) \frac{\omega}{1-\lambda} .
$$

For $\omega$ sufficiently small and $p<1-p$ the strategy that involves going bankrupt in the no devaluation state yields a lower expected cost of borrowing. To see why $R^{a}$ can be smaller in this equilibrium than in an economy with guarantees contingent on $S=s_{2}$, note that the equilibrium value of $R^{a}$ is given by:

$$
R^{a}=\frac{F}{s_{1}}\left[p R^{*}+\psi^{\prime}(L)\right] .
$$

It can be shown that as $\omega \rightarrow 0$ the equilibrium value of $L$ converges to $L_{g}$. Comparing (6.4) with (5.7) it follows that if $p<1-p$, then $R^{a}$ is lower than $R_{g}^{a}$.

In summary, providing uncontingent guarantees lowers the ask interest rate and creates a lending boom. However, it also makes the financial system extremely fragile in the sense that banks survive only in the unlikely event that the currency is devalued. If nothing else this strongly suggests that if, for some reason, a government feels compelled to provide loan guarantees, these should be made contingent on a devaluation occurring.

\section{Introducing Real Uncertainty}

In this section we analyze the effects of government guarantees when exchange rate risk takes the form of lower repayment rates on the loans made by banks to firms in the devaluation state. To focus our analysis we abstract from the type of risk analyzed in the previous section, namely the risk that arises when banks borrow dollars but lend domestic currency. As we show below, our basic results do not depend on which type of exchange rate risk we consider.

Suppose that in any given period a fraction $\Phi$ of the firms repay their bank loans. To simplify we assume that $\Phi$ can take on only two values: $\Phi=\{\phi, 1\}$ where $\phi<1$. To concentrate on the effect of bankruptcies associated with devaluations we suppose that $\operatorname{Pr}\left(\Phi=\phi \mid S=s_{1}\right)=0$. To allow for imperfect correlation between 
exchange rate devaluations and firm bankruptcies we assume that $\operatorname{Pr}(\Phi=\phi \mid S=$ $\left.s_{2}\right)=q$.

We define profits to be

$$
\pi\left(\Phi, S, R^{b}\right)=R^{a} L \Phi-R^{b} L-\psi(L)+(1-\delta) K+x\left(\frac{1}{F}-\frac{1}{S}\right) .
$$

As before we restrict $x$ to take on values such that the bank will be able to settle its forward position in all states of the world:

$$
\text { if } \pi\left(\Phi, S, R^{b}\right)<0 \text { then }(1-\lambda)\left[R^{a} L \Phi-\psi(L)+(1-\delta) K+x\left(\frac{1}{F}-\frac{1}{S}\right)\right] \geq \omega \text {. }
$$

As in section 4 , we consider the case in which the quantity of bank loans $L$ is fixed. Since our results hold for any value of $L$ they can readily be generalized to the case where $L$ is endogenous. The effect of guarantees on bank hedging strategies is summarized by the following two propositions.

Proposition 7.1. Consider an economy in which there are no guarantees. Suppose $L$ is fixed, $0<\lambda<1$ and condition (7.1) is satisfied. Then fully hedging loan default risk, whenever feasible, is optimal.

Proof: See Appendix.

We now discuss the intuition underlying this proposition. Under full hedging the expected cost of borrowing is $R^{*} L$. There are three alternatives to full hedging: strategy $I$ is to default when $S=s_{2}$ regardless of the value of $\Phi$; strategy $I I$ is to default when $S=s_{2}$ and $\Phi=\phi$; strategy $I I I$ is to default when $S=s_{1}$.

Under strategy $I$ we have

$$
\begin{aligned}
R^{*} L= & (1-p) R^{b} L+p q\left\{(1-\lambda)\left[R^{a} L \phi+(1-\delta) K-\psi(L)+x\left(\frac{1}{F}-\frac{1}{s_{2}}\right)\right]-\omega\right\}+ \\
& p(1-q)\left\{(1-\lambda)\left[R^{a} L+(1-\delta) K-\psi(L)+x\left(\frac{1}{F}-\frac{1}{s_{2}}\right)\right]-\omega\right\}
\end{aligned}
$$


so that the optimal strategy is to reduce the residual value of the bank when $\Phi=\phi$ to zero. Note that we cannot reduce the residual value of the bank when $\Phi=1$ to zero since that would violate (7.1) when $\Phi=\phi$. This just means that cross-hedging loan repayment risk with forward contracts on the exchange rate is less efficient that if banks could use a hedging instrument with payoffs contingent on $\Phi$. Given the optimal value of $x$ we have

$$
R^{*} L=(1-p) R^{b} L+p(1-q)(1-\lambda)(1-\phi) R^{a} L .
$$

The expected cost of borrowing under strategy $I$ is

$$
\begin{aligned}
E C B_{I}= & (1-p) R^{b} L+p q\left[R^{a} L \phi+(1-\delta) K-\psi(L)+x\left(\frac{1}{F}-\frac{1}{s_{2}}\right)\right]+ \\
& p(1-q)\left[R^{a} L+(1-\delta) K-\psi(L)+x\left(\frac{1}{F}-\frac{1}{s_{2}}\right)\right] \\
= & (1-p) R^{b} L+p q \frac{\omega}{1-\lambda}+p(1-q)\left[\frac{\omega}{1-\lambda}+(1-\phi) R^{a} L\right] \\
= & R^{*} L+p \lambda(1-q)(1-\phi) R^{a} L+p \frac{\omega}{1-\lambda} .
\end{aligned}
$$

Under strategy $I I$ we have

$$
R^{*} L=(1-p q) R^{b} L+p q\left\{(1-\lambda)\left[R^{a} L \phi+(1-\delta) K-\psi(L)+x\left(\frac{1}{F}-\frac{1}{s_{2}}\right)\right]-\omega\right\}
$$

so that the optimal strategy is to choose the smallest $x$ consistent with strategy II. Notice that this value of $x$ can be no less than the smallest $x$ consistent with strategy $I$. Thus, the expected cost of borrowing under strategy $I I$ is

$$
\begin{aligned}
E C B_{I I} & =(1-p q) R^{b} L+p q\left\{R^{a} L \phi+(1-\delta) K-\psi(L)+x\left(\frac{1}{F}-\frac{1}{s_{2}}\right)\right\} \\
& \geq R^{*} L+p q \frac{\omega}{1-\lambda} .
\end{aligned}
$$

Under strategy $I I I$ we have

$$
R^{*} L=p R^{b} L+(1-p)\left\{(1-\lambda)\left[R^{a} L+(1-\delta) K-\psi(L)+x\left(\frac{1}{F}-\frac{1}{s_{1}}\right)\right]-\omega\right\},
$$


so that the optimal strategy is to reduce the residual value of the firm in the no devaluation state to zero. So we have

$$
R^{*} L=p R^{b} L
$$

The expected cost of borrowing under strategy $I I I$ is

$$
\begin{aligned}
E C B_{I I I} & =p R^{b} L+(1-p)\left\{R^{a} L+(1-\delta) K-\psi(L)+x\left(\frac{1}{F}-\frac{1}{s_{1}}\right)\right\} \\
& =R^{*} L+(1-p) \frac{\omega}{1-\lambda} .
\end{aligned}
$$

Comparing these three strategies we conclude that full hedging minimizes the expected cost of borrowing.

Proposition 7.2. Consider an economy with guarantees. Suppose $L$ is fixed, $\omega<(1-\lambda) R^{*} L, 0<\lambda<1$ and the condition (7.1) is satisfied. Then it is not optimal for banks to fully hedge loan default risk.

Proof: See Appendix.

The logic behind this proposition can be explained as follows. The expected cost of borrowing under full hedging is $R^{*} L$. If

$$
\omega<(1-\lambda)\left[R^{*} L-(1-\phi) R^{a} L\right]
$$

strategy $I$ is feasible and the expected cost of borrowing is

$$
\begin{aligned}
E C B_{I}= & (1-p) R^{*} L+p q\left\{R^{a} L \phi+(1-\delta) K-\psi(L)+x\left(\frac{1}{F}-\frac{1}{s_{2}}\right)\right\}+ \\
& p(1-q)\left\{R^{a} L+(1-\delta) K-\psi(L)+x\left(\frac{1}{F}-\frac{1}{s_{2}}\right)\right\} \\
= & (1-p) R^{*} L+p q\left\{\frac{\omega}{1-\lambda}\right\}+p(1-q)\left\{\frac{\omega}{1-\lambda}+R^{a} L(1-\phi)\right\} \\
= & R^{*} L-p\left[R^{*} L-(1-\phi) R^{a} L-\frac{\omega}{1-\lambda}\right]-p q(1-\phi) R^{a} L<R^{*} L
\end{aligned}
$$


It turns out that when (7.2) holds, the lowest value of $x$ consistent with strategy II implies that

$$
E C B_{I}<E C B_{I I}=R^{*} L-p q(1-\phi) R^{a} L<R^{*} L
$$

so that strategy $I$ is optimal.

When (7.2) does not hold, strategy $I$ is not feasible. The expected cost of borrowing under strategy $I I$ is

$$
\begin{aligned}
E C B_{I I} & =(1-p q) R^{*} L+p q\left\{R^{a} L \phi+(1-\delta) K-\psi(L)+x\left(\frac{1}{F}-\frac{1}{s_{2}}\right)\right\} \\
& =R^{*} L-p q\left(R^{*} L-\frac{\omega}{1-\lambda}\right)<R^{*} L
\end{aligned}
$$

As before, for strategy $I I I$ we have

$$
E C B_{H I I}=R^{*} L+(1-p) \frac{\omega}{1-\lambda}>R^{*} L
$$

So, we have shown that if $\omega<(1-\lambda) R^{*} L$, full hedging is not optimal, since it is dominated by strategy $I$ and/or strategy $I I$.

We conclude that for any admissible $L$ it is not optimal to fully hedge. It follows that if $L$ is endogenous, full hedging will continue to be a dominated strategy.

\section{Macroeconomic Implications}

In this section we embed our banking model into a general equilibrium environment. This allows us to endogenize the demand for bank loans, $D\left(R^{a}\right)$, and derive the equilibrium implications of government guarantees for output, employment, real wages, and interest rates. Throughout this section we concentrate on the type of exchange risk analyzed in Sections 3 and 4 and abstract from loan default on the part of firms. It would be straightforward to accommodate the latter. 


\subsection{The Model Economy}

Before describing the detailed problems of the agents in the economy we provide an overview of the timing of their interactions. This timing was chosen so that banks face exchange rate risk and there are no wage rigidities. We abstract from labor market imperfections to focus on the role of banking frictions per se in our model economy. ${ }^{17}$ With this in mind we divide each period into three subperiods. In subperiod 1 banks borrow funds from abroad, enter into forward contracts and make loans to firms. In addition firms hire labor at a market clearing real wage rate and enter into forward contracts. Finally the household makes its portfolio decisions. In subperiod 2 , the exchange rate is realized, forward contracts are settled and firms pay labor in units of the local currency. In subperiod 3 production and consumption occur. In addition bankruptcy costs, if any, are incurred and foreign loans are repaid.

\section{Households}

There is a continuum of unit measure of identical households who maximize utility defined over sequences of consumption, $C_{t}$, and labor supply, $H_{t}$ :

$$
U=E_{0} \sum_{t=0}^{\infty} \beta^{t} u\left(C_{t}, H_{t}\right), \quad 0<\beta<1 .
$$

Here $E_{0}$ denotes the expectation conditional on the representative household's time zero information set. In order to obtain analytical results we make three simplifying assumptions. First, we assume that momentary utility takes the form:

$$
u\left(C_{t}, H_{t}\right)=\log \left(C_{t}-\frac{1}{\eta} H_{t}^{\eta}\right), \quad \eta>1 .
$$

The advantage of this specification is that the labor supply depends only on the real wage rate (see (8.1) below). Second, we assume that the household's real financial wealth, $a_{t}$, is invested in a perfectly diversified international portfolio

\footnotetext{
${ }^{17}$ Other things equal the presence of nominal wage rigidities would generate upwards pressure on aggregate employment and output following a devaluation. This is because the real wage would fall if the domestic price level rose.
} 
that yields a constant dollar-denominated gross rate of return $R^{*}$. Both domestic firms and banks are part of this portfolio and the risk associated with their returns is perfectly diversifiable. Under these assumptions, the budget constraint of the representative household is:

$$
\frac{M_{t+1}^{d}}{P_{t}}+a_{t+1}=\frac{M_{t}^{d}}{P_{t}}+R^{*} a_{t}+w_{t} H_{t}-C_{t}+\tau_{t} .
$$

The variable $\tau_{t}$ represents lump sum transfers from the government, $M_{t}^{d}$ denotes money holdings at the beginning of period $t, w_{t}$ is the time $t$ real wage rate, and $P_{t}$ denotes the time $t$ price level.

The household faces a cash-in-advance constraint on consumption:

$$
P_{t} C_{t} \leq M_{t}^{d}+P_{t} w_{t} H_{t}
$$

Throughout we assume that $R^{*}>1$, so that this previous constraint holds with equality.

It is useful to note that the household's first order condition for $H_{t}$ implies:

$$
H_{t}=w_{t}^{1 /(\eta-1)}
$$

so that $1 /(\eta-1)$ is the elasticity of labor supply.

Output Producers

There is a continuum of measure $N$ perfectly competitive firms each of which produces the single consumption good in the economy using labor, $h$, according to the following decreasing returns to scale technology:

$$
y=f(h)-\zeta,
$$

Here $f^{\prime}(h)>0, f^{\prime \prime}(h)<0, f(0)=0$ and $f^{\prime}(0)=\infty$. The parameter $\zeta>0$ represents a fixed cost of production.

Before the exchange rate is realized, firms hire labor in a competitive spot market at the real wage rate $w=W / P$. Firms borrow $d$ units of local currency 
from banks at the gross interest rate $R^{a}$, and sell $x^{f}$ units of the local currency in the forward market. We impose the restriction that the firm must have in hand a sufficient amount of the local currency to pay its nominal wage bill, $W h$, at the end of the period, regardless of the realized value of the exchange rate. This is equivalent to the restriction:

$$
w h \leq \frac{d}{S}+x^{f}\left(\frac{1}{F}-\frac{1}{S}\right) \quad \forall S .
$$

The firm's real profit, $\pi_{f}$, is given by:

$$
\pi_{f}=f(h)-\zeta-w h-\left(R^{a}-1\right) \frac{d}{S}+x^{f}\left(\frac{1}{F}-\frac{1}{S}\right) .
$$

The representative firm's problem is to maximize expected profit

$$
E \pi_{f}=f(h)-\zeta-w h-\left(R^{a}-1\right) \frac{d}{F}
$$

subject to (8.3).

Under the fixed exchange rate, since borrowing is costly, the constraint (8.3) will hold with equality for all possible $S$. Evaluating (8.3) at $S$ equal to $s_{1}$ and $s_{2}$, we obtain a system of two equations in $d$ and $x^{f}$. Solving this system yields $d=x^{f}=F w h$. Once a devaluation occurs, there is no uncertainty, and from then on the forward rate is the same as the future spot rate, i.e. $F=S$, and we have $d=F w h=S w h$.

Under either exchange rate regime, substituting $d=F w h$ into (8.4) we see that the firm chooses $h$ to maximize

$$
E \pi_{f}=f(h)-\zeta-R^{a} w h
$$

The first order condition for $h$ implies:

$$
f^{\prime}(h)=R^{a} w
$$




\section{Banks}

The maximization problem of the representative bank is specified in section 4 .

\section{Government}

The money supply, $M_{t}^{S}$, follows a stochastic process governed by the stochastic process for the exchange rate regime described in Section 3. In the fixed exchange rate regime, $e_{t}=1$, the money supply follows a deterministic sequence $M_{t}^{S}=$ $M_{1 t}$ such that $S_{t}=s_{1}$. In the devaluation regime the money supply follows a deterministic sequence, $M_{t}^{S}=M_{2 t}$, such that the exchange rate is $S_{t}=\gamma^{t-t^{*}} s_{2}$, where $t^{*}$ is the date at which the devaluation regime begins.

The government's budget constraint is:

$$
\tau_{t}= \begin{cases}\left(M_{1 t+1}-M_{1 t}\right) / s_{1} & \text { for } t<t^{*} \\ \left(M_{2 t+1}-M_{2 t}\right) / s_{2}-\Gamma & \text { for } t=t^{*} \\ \left(M_{2 t+1}-M_{2 t}\right) /\left(s_{2} \gamma^{t-t^{*}}\right) & \text { for } t>t^{*}\end{cases}
$$

with $M_{1 t^{*}}=M_{2 t^{*}}$, where $\Gamma$ is the payment made to the bank's foreign creditors when a devaluation takes place. In the absence of government guarantees $\Gamma=0$. In an economy with guarantees $\Gamma$ is given by: ${ }^{18}$

$$
\Gamma=B R^{*} L-B\left\{(1-\lambda)\left[\frac{R^{a} s_{1}}{s_{2}} L-\psi(L)+(1-\delta) k+x\left(\frac{1}{F}-\frac{1}{s_{2}}\right)\right]-\omega\right\}
$$

Recall that $B$ denotes the number of banks. Consequently the first term on the right hand side of (8.7), $B R^{*} L$, is the total dollar amount owed by domestic banks to foreign creditors. The second term represents the total residual value of the domestic bank system in the bankruptcy state, net of bankruptcy costs.

\section{Equilibrium}

We assume free entry into the goods producing sector, so that:

$$
E \pi_{f}=0 .
$$

Labor market clearing implies:

\footnotetext{
${ }^{18}$ To economize on notation we wrote this equation for the case in which banks default in the devaluation state, since that is the scenario we focus on.
} 


$$
N h=H .
$$

The total supply of goods is given by:

$$
Y=y N
$$

We now provide a definition of the equilibrium of our model economy which applies both to economies with and without government guarantees.

Definition. An equilibrium is a set of stochastic processes for

(i) the household's decision variables $\left\{C_{t}, H_{t}, a_{t+1}, M_{t+1}^{d}\right\}$;

(ii) the firm's employment, borrowing and hedging decisions $\left\{h_{t}, d_{t}, x_{t}^{f}\right\}$;

(iii) the bank's loan and hedging decisions $\left\{L_{t}, x_{t}\right\}$;

(iv) the government policy variables $\left\{M_{t}, \tau_{t}\right\}$;

(v) the number of banks, $B_{t}$, and the number of output firms, $N_{t}$; and

(vi) the real wage, $w_{t}$, the price level, $P_{t}$, the forward exchange rate, $F_{t}$, and the interest rate, $R_{t}^{a}$, with the following properties.

(a) the government budget constraint (8.6) holds,

(b) $\left\{C_{t}, H_{t}, a_{t+1}, M_{t+1}^{d}\right\}_{t=0}^{\infty}$ solve the household's problem given $\left\{w_{t}, P_{t}, \tau_{t}\right\}_{t=0}^{\infty}$;

(c) $\left\{h_{t}, d_{t}, x_{t}^{f}\right\}_{t=0}^{\infty}$ solves the firm's problem given $\left\{w_{t}, P_{t}, R_{t}^{a}\right\}_{t=0}^{\infty}$;

(d) $\left\{L_{t}, x_{t}\right\}_{t=0}^{\infty}$ solve the bank's problem given $\left\{R_{t}^{a}, P_{t}, S_{t}\right\}_{t=0}^{\infty}$;

(e) the PPP condition (3.1) holds;

(f) the forward currency market clears (3.3);

(g) the money market clears, $M_{t}^{S}=M_{t}^{d}$;

(h) the exchange rate path is given by (3.2);

(i) the labor market clearing condition (8.9) holds;

(j) the credit market clears, $S_{t-1} B_{t} L_{t}=N_{t} F_{t} w_{t} h_{t}$;

(k) the free entry conditions in the banking sector holds: $V=R^{*} K$, where $V$ is given by (3.5);

(1) the free entry condition in the output sector, (8.8), holds. 


\subsection{Characterizing the Equilibrium}

In this subsection we characterize the equilibrium of the model economy with and without government guarantees. Given our assumption that households can borrow and lend in world capital markets at rate $R^{*}$, production and consumption decisions can be decoupled. In particular, we can solve for equilibrium employment, $H$, output, $Y$, real wages, $w$, and the interest rate, $R^{a}$, without deriving the equilibrium stochastic processes for consumption and the money supply. ${ }^{19}$ As emphasized in the introduction, the focus of this paper is on the effects of government guarantees on the banking industry and on aggregate economic activity. Accordingly, we restrict ourselves to characterizing the behavior of $H, Y, w$, and $R^{a}$.

For the versions of the model with and without government guarantees, we proceed as follows. We first derive an equilibrium demand schedule that relates the demand for loans to $R^{a}$. We then use our previous analysis of the banking system to determine the equilibrium value of $R^{a}$. Finally, we show how government guarantees influence the equilibrium values of $H, Y, w$, and $R^{a}$.

To derive the equilibrium relationship between the total demand for loans and $R^{a}$ note that (8.4), (8.5) and (8.8) imply that the equilibrium number of hours employed by each firm is the solution to:

$$
f(h)-f^{\prime}(h) h=\zeta .
$$

Given $h$ and $R_{t}^{a}$, equation (8.5) determines the real wage, $w_{t}=f^{\prime}(h) / R_{t}^{a}$, which in turn determines total labor supply via relation $(8.1), H_{t}=\left[f^{\prime}(h) / R_{t}^{a}\right]^{1 /(\eta-1)}$. Since $N_{t} h=H_{t}$ we then obtain the number of firms $N_{t}=\left[f^{\prime}(h) / R_{t}^{a}\right]^{1 /(\eta-1)} / h$.

The demand for loans in units of local currency is $N_{t} d_{t}$. Since loans are made prior to the realization of the time $t$ exchange rate, the demand for loans in units of foreign currency is $N_{t} d_{t} / S_{t-1}$. Substituting in the fact that $d_{t}=F_{t} w_{t} h$ and the

\footnotetext{
${ }^{19}$ For an analysis of consumption in an open economy model where government policy follows a regime switching process similar to ours see Calvo and Drazen (1998).
} 
expressions for $N_{t}$ and $w_{t}$ above, we have the demand for loans as

$$
D\left(R_{t}^{a}\right)=\frac{N_{t} d_{t}}{S_{t-1}}=\frac{F_{t}}{S_{t-1}}\left[\frac{f^{\prime}(h)}{R_{t}^{a}}\right]^{\eta /(\eta-1)}
$$

where $h$ is the solution to (8.11). Since $\eta>1, D^{\prime}\left(R_{t}^{a}\right)<0$, which is consistent with our industry equilibrium analysis. Notice that

$$
\frac{F_{t}}{S_{t-1}}= \begin{cases}\frac{\gamma}{(1-p) \gamma+p} & \text { for } t \leq t^{*} \\ \gamma & \text { for } t>t^{*}\end{cases}
$$

In Section 4 we showed that the loans per bank, $L$, and $R^{a}$ are determined by the equilibrium of the banking industry. With no guarantees these are given by equations (5.1) and (5.2), respectively. With guarantees they are given by (5.6) and (5.7), respectively. The equilibrium amount of loans in the economy is determined by substituting either (5.7) or (5.2) in (8.12), depending on whether or not there are government guarantees.

Given the equilibrium value of $D\left(R_{t}^{a}\right)$ and the loans per bank, $L$, we can determine the number of banks as

$$
B_{t}=\frac{D\left(R_{t}^{a}\right)}{L} .
$$

Given the previous results, the equilibrium stochastic processes for consumption, the price level, and the money supply process consistent with (3.2) can be characterized by solving the household's problem as well as imposing PPP and money market clearing.

\subsection{The Effects of A Devaluation}

Consider first a situation with no government guarantees. Since banks are fully hedged no bankruptcies occur when a devaluation takes place. There is no uncertainty from time $t^{*}$ on so, after the devaluation, banks can borrow at rate $R^{*}$ and their objective function is given by:

$$
V=\frac{S_{t-1}}{S_{t}} \bar{R}_{t}^{a} L-R^{*} L-\psi(L)+(1-\delta) K
$$


Here $\bar{R}_{t}^{a}$ is the value of $R^{a}$ after the devaluation. The first order condition for $L$ implies that the post-devaluation borrowing rate is a constant

$$
\bar{R}^{a}=\gamma\left[R^{*}+\psi^{\prime}(L)\right]
$$

Here we used the fact that $S_{t} / S_{t-1}=\gamma$ and the fact that the value of $L$ is still given by:

$$
\psi^{\prime}(L) L-\psi(L)+(1-\delta) K=R^{*} K
$$

and is unaffected by the devaluation. Proceeding as above we can deduce the equilibrium level of output, real wages and employment. Recall that prior to the devaluation $R^{a}$ is given by (5.2), which can be written as:

$$
R^{a}=\frac{\gamma}{(1-p) \gamma+p}\left[R^{*}+\psi^{\prime}(L)\right]
$$

Since $\gamma>1$ it follows that $\bar{R}^{a}>R^{a}$. Equations (8.12), (8.14) and (8.13) imply that the total demand for loans and the number of banks decline after a devaluation:

$$
D\left(\bar{R}^{a}\right)=[(1-p) \gamma+p]^{-1 /(\eta-1)} D\left(R^{a}\right)
$$

Equations (8.11) and (8.2) imply that $h$ and $y$ are invariant. Considered sequentially, equations (8.5), (8.1), (8.9), and (8.10) imply that real wages, employment, the number of firms in the output sector and aggregate output fall.

Now consider the situation in which there are government guarantees. Since banks are not hedged they declare bankruptcy when a devaluation occurs, so that bankruptcy costs are incurred. Next, recall that prior to the devaluation $R^{a}$ is given by:

$$
R^{a}=\frac{\gamma}{(1-p) \gamma+p}\left[(1-p) R^{*}+\psi^{\prime}\left(L_{g}\right)\right]
$$

where for $\omega$ arbitrarily close to zero $L_{g} \cong L$.

Since there is no uncertainty after the devaluation, government guarantees play no role in the economy, so that $\bar{R}^{a}$ is given by (8.15). Because the interest 
rate is lower to start with in the economy with government guarantees, the rise in $R^{a}$ when a devaluation takes place is larger in an economy with government guarantees. It follows that the severity of the declines in real wages, employment, the number of banks, the number of firms, and aggregate output are all larger in an economy with guarantees.

\section{Conclusions}

This paper analyzed the connection between exchange rate devaluations and banks' hedging behavior. We argued that the presence of government guarantees to banks' creditors completely eliminates banks incentives to hedge exchange rate risk. So while the policy lowers the interest rate on bank loans and raises aggregate output, it comes at a cost. The banking system becomes fragile. In the event of a devaluation, banks renege on their debt and go bankrupt.

We conclude by discussing some shortcomings of our analysis. To preserve the analytical tractability of our model we made several important simplifying assumptions. First, we assumed that there is no uncertainty about the exchange rate path once a devaluation occurs: the currency depreciates at rate $\gamma$ per unit of time. Aside from the counterfactual nature of this assumption, it implies that economies with and without guarantees look identical once the devaluation occurs. This would not be the case if there was ongoing exchange rate uncertainty. Second, we assumed that devaluations are exogenous events, whose probability is unrelated to the state of the economy. While this assumption was useful, it abstracts from the very real possibility that the state of a country's banking system affects speculators incentives to attack a currency as well as a government's incentives to defend it. We are exploring these connections in ongoing research. Finally, we did not address the question of why governments often provide implicit guarantees to banks. We suspect that the answer is related to our model's prediction that such policies generate booms in aggregate activity. Understanding why policymakers focus on this benefit (as well as others not discussed in this paper), 
rather than the costs is an important task that will no doubt involve political economy type considerations.

\section{References}

Akerlof, George and Paul Romer (1993) "Looting: The Economic Underworld of Bankruptcy for Profit," Brookings Papers in Economic Activity, 2: 1-60.

Albuquerque, Rui (1999) "Optimal Currency Hedging," Working Paper, University of Rochester.

Caballero, Ricardo and Arvind Krishnamurthy (1998) "Emerging Markets Crises: An Assets Markets Perspective," Working Paper, MIT.

Calomiris, Charles (1998) "The IMF'S Imprudent Role as Lender of Last Resort," The Cato Journal, 17.

Calvo, Guillermo and Allan Drazen (1998) "Uncertain Duration of Reforms: Dynamic Implications," Macroeconomic Dynamics.

Chang, Roberto and Andres Velasco (1999) "Iliquidity and Crises in Emerging Markets: Theory and Policy," Working Paper, New York University.

Chari, V.V., Lawrence Christiano, and Martin Eichenbaum (1995) "Inside Money, Outside Money and Short Term Interest Rates," Journal of Money, Credit and Banking, 1354-1386.

Christiano, Lawrence and Martin Eichenbaum (1992) "Liquidity Effects and the Monetary Transmission Mechanism," American Economic Review, 82: 346353.

Delhaise, Philippe F. (1998) Asia in Crisis: The Implosion of the Banking and Finance Systems. Singapore: John Wiley and Sons.

Diaz-Alejandro, Carlos (1985) "Goodbye Financial Repression, Hello Financial Crash," Journal of Development Economics, 19: 1-4.

Drees, Burkhard and Ceyla Pazarbaşioğlu (1998) "The Nordic Banking Crises: Pitfalls in Financial Liberalization?" International Monetary Fund Occasional Paper 161. 
Edwards, Sebastian and Carlos Vegh (1997) "Banks and Macroeconomic Disturbances under Predetermined Exchange Rates," Journal of Monetary Economics, 40: 239-278.

Eichengreen, Barry and Albert Fishlow (1998) "Contending with Capital Flows: What is Different about the 1990s?" in Miles Kahler ed. Capital Flows and Financial Crises. Ithaca, NY: Cornell University Press.

Folkerts-Landau, David (1997) International Capital Markets: Developments, Prospects, and Key Policy Issues, November. Washington, DC: International Monetary Fund.

Garber, Peter and Subir Lall (1998) "Derivative Products in Exchange Rate Crises," in Glick, Reuven Managing Capital Flows and Exchange Rates: Perspectives from the Pacific Basin, New York, Cambridge University Press.

Gavin, Michael and Ricardo Hausmann (1996) "The Roots of Banking Crises: The Macroeconomic Context," in Ricardo Hausmann and Liliana RojasSuárez eds. Banking Crises in Latin America. Washington, DC: InterAmerican Development Bank.

International Monetary Fund (1998) International Capital Markets: Developments, Prospects, and Key Policy Issues, World Economic and Financial Surveys, Washington.

International Monetary Fund (1999) "IMF-Supported Programs in Indonesia, Korea and Thailand: A Preliminary Assessment."

Jackson, Karl. D (1999) "Introduction: the Roots of the Crisis," in Karl D. Jackson ed. Asian Contagion: The Causes and Consequences of a Financial Crisis. Boulder, CO: Westview Press.

Kaminsky, Graciela and Carmen Reinhart (1999) "The Twin Crises: The Causes of Banking and Balance-of-Payments Problems," American Economic Review, forthcoming.

Kareken, John and Neil Wallace (1978) "Deposit Insurance and Bank Regulation: A Partial Equilibrium Exposition," Journal of Business, 51, 413-438.

Krueger, Anne and Aaron Tornell (1999) "The Role of Bank Restructuring in Recovering from Crises: Mexico 1995-98," National Bureau of Economic Research Working Paper 7042. 
Lane, Timothy, Atish Ghosh, Javier Hamann, Steven Phillips, Marianne SchulzeGhattas, and Tsidi Tsikata (1999) "IMF-Supported Programs in Indonesia, Korea and Thailand: A Preliminary Assessment," Working Paper, International Monetary Fund, January.

Merton, Robert (1987) "An Analytic Derivation of the Cost of Deposit Insurance and Loan Guarantees. An Application of Modern Option Pricing Theory," Journal of Banking and Finance, 1: 3-11.

Mishkin, Frederic (1996) "Understanding Financial Crises: A Developing Country Perspective," in Bruno, Michael and Boris Pleskovic (eds.) Annual World Bank Conference on Development Economics 1996, 29-62. Washington, DC: World Bank.

Modigliani, Franco and Merton Miller (1958) "The Cost of Capital, Corporation Finance, and the Theory of Investment," American Economic Review, 48, 261-297.

Nyberg, Peter and Vesa Vihriälä (1993) "Finish Banking Problems: Handling and Prospects," Bank of Finland Bulletin, 67, 3-7.

Obstfeld, Maurice (1998) "The Global Capital Market: Benefactor or ' lenace?" Journal of Economic Perspectives, 12, 9-30. 


\section{A. Appendix}

\section{A.1. Proof of Proposition 5.1}

\section{A.1.1. Preliminaries}

It will be useful to define two functions

$$
\pi\left(x, L \mid R^{a}, R^{b}, S\right) \equiv R^{a} \frac{s_{1}}{S} L-R^{b} L-\psi(L)+(1-\delta) K+x\left(\frac{1}{F}-\frac{1}{S}\right),
$$

and

$$
\begin{aligned}
\pi^{*}\left(x, L \mid R^{a}, S\right) & \equiv R^{a} \frac{s_{1}}{S} L-R^{*} L-\psi(L)+(1-\delta) K+x\left(\frac{1}{F}-\frac{1}{S}\right) \\
& =\pi\left(x, L \mid R^{a}, R^{*}, S\right)
\end{aligned}
$$

In the proof we will occasionally drop the notation that indicates the dependence of $\pi$ and $\pi^{*}$ on some of their arguments.

For a given value of $R^{a}$, banks choose $(x, L) \in \Omega\left(R^{a}\right)$ to maximize

$$
V=(1-p) \max \left\{\pi\left(s_{1}\right), 0\right\}+p \max \left\{\pi\left(s_{2}\right), 0\right\} .
$$

The set $\Omega=\Omega_{1} \cup \Omega_{2} \cup \Omega_{3} \cup \Omega_{4} \cdot{ }^{20}$ The set $\Omega_{1}$ consists of those $(x, L)$ pairs consistent with the bank being fully hedged, i.e. $\Omega_{1}=\left\{(x, L) \mid L \geq 0, \pi^{*}(x, L) \geq 0, \forall S\right\}$. When the bank is not fully-hedged, we impose the restriction that it cannot reduce its recoverable residual value below the fixed cost of bankruptcy in either state of the world, i.e. if $\pi(S)<0$ then

$$
(1-\lambda)\left[R^{a} \frac{s_{1}}{S} L-\psi(L)+(1-\delta) K+x\left(\frac{1}{F}-\frac{1}{S}\right)\right] \geq \omega
$$

The other sets are defined as $\Omega_{2}=\left\{(x, L) \notin \Omega_{1} \mid \pi\left(s_{1}\right) \geq 0, \pi\left(s_{2}\right)<0,(\mathrm{~A} .4)\right\}, \Omega_{3}=$ $\left\{(x, L) \notin \Omega_{1} \mid \pi\left(s_{1}\right)<0, \pi\left(s_{2}\right) \geq 0,(\mathrm{~A} .4)\right\}$ and $\Omega_{4}=\left\{(x, L) \notin \Omega_{1} \mid \pi\left(s_{1}\right)<0, \pi\left(s_{2}\right)<\right.$ $0,($ A.4) $\}$. Before proceeding with the proof, we characterize $\Omega_{1}$.

\section{A.1.2. Constructing $\Omega_{1}$}

We can construct $\Omega_{1}$ by finding the loci of points at which $\pi^{*}\left(x, L \mid R^{a}, s_{i}\right)=0$ for $i=1$ and 2. These loci are illustrated in Figure 1 as $\underline{X}(L)$ and $\bar{X}(L)$.

\footnotetext{
${ }^{20}$ The sets $\Omega_{i}, i=1,2,3,4$, depend on the ask rate $R^{a}$. We drop this dependence for notational convenience.
} 
We have $\pi^{*}\left(s_{1}\right)=0$ if

$$
\left(R^{a}-R^{*}\right) L-\psi(L)+(1-\delta) K+x\left(\frac{1}{F}-\frac{1}{s_{1}}\right)=0
$$

or

$$
x=\bar{X}(L) \equiv \frac{\left(R^{a}-R^{*}\right) L-\psi(L)+(1-\delta) K}{\frac{1}{s_{1}}-\frac{1}{F}} .
$$

The $L$-intercept of $\bar{X}(L)$ is at $L_{\bar{X}}$, given by

$$
\left(R^{a}-R^{*}\right) L_{\bar{X}}-\psi\left(L_{\bar{X}}\right)+(1-\delta) K=0 .
$$

The $x$-intercept of $\bar{X}(L)$ is at

$$
x=\frac{(1-\delta) K-\psi(0)}{\frac{1}{s_{1}}-\frac{1}{F}}>0 .
$$

Also

$$
\bar{X}^{\prime}(L)=\frac{R^{a}-R^{*}-\psi^{\prime}(L)}{\frac{1}{s_{1}}-\frac{1}{F}}
$$

which is greater than zero for $0 \leq L<L_{1}$, and is less than zero for $L>L_{1}$ where $R^{a}-R^{*}=\psi^{\prime}\left(L_{1}\right){ }^{21}$ And we have

$$
\bar{X}^{\prime \prime}(L)=-\frac{\psi^{\prime \prime}(L)}{\frac{1}{s_{1}}-\frac{1}{F}} \leq 0,
$$

from the convexity of $\psi$. So $\bar{X}(L)$ is concave.

We have $\pi^{*}\left(s_{2}\right)=0$ if

$$
\left(R^{a} \frac{s_{1}}{s_{2}}-R^{*}\right) L-\psi(L)+(1-\delta) K+x\left(\frac{1}{F}-\frac{1}{s_{2}}\right)=0
$$

or

$$
x=\underline{X}(L) \equiv-\frac{\left(R^{a \frac{s_{1}}{s_{2}}}-R^{*}\right) L-\psi(L)+(1-\delta) K}{\frac{1}{F}-\frac{1}{s_{2}}} .
$$

The $L$-intercept of $\underline{X}(L)$ is at $L_{\underline{X}}$, given by

$$
\left(R^{a} \frac{s_{1}}{s_{2}}-R^{*}\right) L_{\underline{X}}-\psi\left(L_{\underline{X}}\right)+(1-\delta) K=0 .
$$

\footnotetext{
${ }^{21}$ If $R^{a}-R^{*}<\psi^{\prime}(0)$ then $L_{1}$ is undefined and $X^{\prime}(L)<0$ for all $L$.
} 
The $x$-intercept of $\underline{X}(L)$ is at

$$
x=-\frac{(1-\delta) K-\psi(0)}{\frac{1}{F}-\frac{1}{s_{2}}}<0 .
$$

Also

$$
\underline{X}^{\prime}(L)=-\frac{\left(R^{a} \frac{s_{1}}{s_{2}}-R^{*}\right)-\psi^{\prime}(L)}{\frac{1}{F}-\frac{1}{s_{2}}}
$$

which is less than zero for $0 \leq L<L_{2}$ and is greater than zero for $L>L_{2}$ where $R^{a} s_{1} / s_{2}-R^{*}=\psi^{\prime}\left(L_{2}\right) .{ }^{22}$ Notice that since

$$
R^{a} \frac{s_{1}}{s_{2}}-R^{*}<R^{a}-R^{*}
$$

we have $L_{\underline{X}}<L_{\bar{X}}$ and $L_{2}<L_{1}$. Finally

$$
\underline{X}^{\prime \prime}(L)=\frac{\psi^{\prime \prime}(L)}{\frac{1}{F}-\frac{1}{s_{2}}}>-\bar{X}^{\prime \prime}(L) \geq 0
$$

which implies that $\underline{X}(L)$ is convex.

Some algebra shows that the point at which $\bar{X}(L)$ and $\underline{X}(L)$ intersect is given by a value of $L$ such that

$$
\frac{s_{1}}{F} R^{a} L-R^{*} L+(1-\delta) K-\psi(L)=0 .
$$

We denote this value $L_{+}$.

Consider Figure 1. For $x<\bar{X}(L), \pi^{*}\left(s_{1}\right)>0$, while for $x>\bar{X}(L), \pi^{*}\left(s_{1}\right)<0$. For $x<\underline{X}(L), \pi^{*}\left(s_{2}\right)<0$ and for $x>\underline{X}(L), \pi^{*}\left(s_{2}\right)>0$. Hence the intersection of the region below $\bar{X}(L)$ and the region above $\underline{X}(L)$ is the region in which $\pi^{*}$ is nonnegative in both states. That is,

$$
\Omega_{1}=\{(x, L) \mid x \leq \bar{X}(L), x \geq \underline{X}(L), L \geq 0\} .
$$

Notice that $R^{b}(x, L)=R^{*}$ for all $(x, L) \in \Omega_{1}$. Clearly $\Omega_{1}$ is a convex set. ${ }^{23}$

In order to prove our propositions we do not need to fully characterize the other three subsets: $\Omega_{2}, \Omega_{3}$ and $\Omega_{4}$. In a more detailed appendix we fully characterize these sets in order to draw the diagram in Figure 1. However, the details of this diagram are not essential to our proof.

\footnotetext{
${ }^{22}$ If $R^{a} s_{1} / s_{2}-R^{*}<\psi^{\prime}(0)$, then $L_{2}$ is undefined and $X^{\prime}(L)<0$ for all $L$.

${ }^{23}$ This does not depend on the existence of the points $L_{1}$ and $L_{2}$. The fact that $\bar{X}(L)$ is concave, while $\underline{Y}(L)$ is convex is sufficient to make $\Omega_{1}$ a convex set.
} 


\section{A.1.3. Solving the Bank's Problem}

We can rewrite the bank's problem as

$$
\max _{(x, L) \in \Omega} V=\max \left\{\max _{(x, L) \in \Omega_{1}} V, \max _{(x, L) \in \Omega_{2}} V, \max _{(x, L) \in \Omega_{3}} V, \max _{(x, L) \in \Omega_{4}} V\right\} .
$$

That is, for any positive $R^{a}$, we can separately maximize expected profits over each of the four subsets of $\Omega$. We can then compare the level of profits for each of these four strategies, and choose the strategy among the four that yields the highest expected profit.

Within $\Omega_{1}$, expected profits are given by

$$
V_{1}(L)=R^{a} \frac{s_{1}}{F} L-R^{*} L-\psi(L)+(1-\delta) K .
$$

So, within $\Omega_{1}$ the value of $x$ is irrelevant to expected profits. Since $\Omega_{1}$ is convex, maximizing $V$ subject to the constraint that $(x, L) \in \Omega_{1}$ is equivalent to maximizing $V_{1}(L)$ for $L \in\left[0, L_{+}\right]$. Differentiating with respect to $L$ we have

$$
\frac{\partial V_{1}}{\partial L}=R^{a} \frac{s_{1}}{F}-R^{*}-\psi^{\prime}(L)
$$

And we have

$$
\frac{\partial^{2} V_{1}}{\partial L^{2}}=-\psi^{\prime \prime}(L) \leq 0 .
$$

Since $\left[0, L_{+}\right]$is compact, and the second order condition for $L$ is satisfied, if there is a solution to the first-order condition for $L<L_{+}$, it will represent a profit maximizing value of $L$. Such a solution would be a value of $L$ such that

$$
R^{a} \frac{s_{1}}{F}-R^{*}=\psi^{\prime}(L)
$$

Another possibility, depending on the value of $R^{a}$, is that the first order condition is not satisfied at any $L \in\left[0, L_{+}\right)$, in which case the optimum must be at $L=0$, where $V_{1}=(1-\delta) K-\psi(0)>0$. Notice that the optimum can never be at $L_{+}$since $V_{1}\left(L_{+}\right)=0$.

Now suppose we maximize $V$ subject to the condition that $(x, L) \in \Omega_{2}$. Expected profits are given by

$$
V_{2}=(1-p)\left[R^{a} L-R^{b} L-\psi(L)+(1-\delta) K+x\left(\frac{1}{F}-\frac{1}{s_{1}}\right)\right]
$$


When we use the expression for $R^{b}$ given by (3.7) we obtain

$$
\begin{gathered}
V_{2}=\left[1-p+p(1-\lambda) \frac{s_{1}}{s_{2}}\right] R^{a} L+(1-\lambda p)[(1-\delta) K-\psi(L)]- \\
p \lambda\left(\frac{1}{F}-\frac{1}{s_{2}}\right) x-R^{*} L-p \omega
\end{gathered}
$$

In this case

$$
\frac{\partial V_{2}}{\partial x}=-p \lambda\left(\frac{1}{F}-\frac{1}{s_{2}}\right)<0 .
$$

Thus, given a value of $L$, the bank will set $x$ to the minimum value it can take within $\Omega_{2}$ for that $L$. This is

$$
x=\underline{Y}(L) \equiv-\frac{R^{a} \frac{s_{1}}{s_{2}} L-\psi(L)+(1-\delta) K-\frac{\omega}{1-\lambda}}{\frac{1}{F}-\frac{1}{s_{2}}} .
$$

If we substitute $x=\underline{Y}(L)$ into the expression for expected profits we find

$$
V_{2}(L)=V_{1}(L)-p \frac{\omega}{1-\lambda} .
$$

Notice that this fact, along with $V_{1}(0)>0, V_{1}\left(L_{+}\right)=0, V_{1}(L)$ concave, and $V_{2}(L) \geq 0$ for all $(x, L) \in \Omega_{2}$, imply that $\left\{L \mid[\underline{Y}(L), L] \in \Omega_{2}\right\} \subset\left[0, L_{+}\right]$. Consequently $\max _{(x, L) \in \Omega_{2}} V<\max _{(x, L) \in \Omega_{1}} V$.

Now suppose we maximize $V$ subject to the condition that $(x, L) \in \Omega_{3}$. Expected profits are given by

$$
V_{3}=p\left[R^{a} \frac{s_{1}}{s_{2}} L-R^{b} L-\psi(L)+(1-\delta) K+x\left(\frac{1}{F}-\frac{1}{s_{2}}\right)\right] .
$$

When we use the expression for $R^{b}$ given by (3.6) we obtain

$$
\begin{gathered}
V_{3}=\left[(1-p)(1-\lambda)+p \frac{s_{1}}{s_{2}}\right] R^{a} L+[1-\lambda(1-p)][(1-\delta) K-\psi(L)]+ \\
\lambda(1-p)\left(\frac{1}{s_{1}}-\frac{1}{F}\right) x-R^{*} L-(1-p) \omega
\end{gathered}
$$

In this case

$$
\frac{\partial V_{3}}{\partial x}=\lambda(1-p)\left(\frac{1}{s_{1}}-\frac{1}{F}\right)>0 .
$$


Thus, given a value of $L$, the bank will set $x$ to the maximum value it can take within $\Omega_{3}$ for that $L$. This is

$$
x=\bar{Y}(L) \equiv \frac{R^{a} L-\psi(L)+(1-\delta) K-\frac{\omega}{1-\lambda}}{\frac{1}{s_{1}}-\frac{1}{F}} .
$$

If we substitute $x=\bar{Y}(L)$ into the expression for expected profits we find

$$
V_{3}(L)=V_{1}(L)-(1-p) \frac{\omega}{1-\lambda} .
$$

Notice that this fact, along with $V_{1}(0)>0, V_{1}\left(L_{+}\right)=0, V_{1}(L)$ concave, and $V_{3}(L) \geq 0$ for all $(x, L) \in \Omega_{3}$, imply that $\left\{L \mid[\bar{Y}(L), L] \in \Omega_{3}\right\} \subset\left[0, L_{+}\right]$. Consequently $\max _{(x, L) \in \Omega_{3}} V<\max _{(x, L) \in \Omega_{1}} V$.

For any $(x, L) \in \Omega_{4}$ expected profits are $V=V_{4}=0$. Since $V_{1}(0)=(1-$ $\delta) K-\psi(0)>0$, we have $\max _{(x, L) \in \Omega_{4}} V<\max _{(x, L) \in \Omega_{1}} V$.

Thus, the profit maximizing $(x, L) \in \Omega_{1}$ for any $R^{a}$.

\section{A.1.4. Equilibrium}

In equilibrium $V=R^{*} K$. The previous subsection showed that in equilibrium $(x, L) \in \Omega_{1}$. We cannot have $L=0$ in equilibrium since $V_{1}(0)=(1-\delta) K-\psi(0)<$ $R^{*} K$. Hence, the only possibility is that an equilibrium with $(x, L) \in \Omega_{1}$ exists in which the first-order condition, (A.5), is satisfied and expected profits are given by

$$
V=\psi^{\prime}(L) L-\psi(L)+(1-\delta) K=R^{*} K
$$

Given the conditions we placed on $\psi$, there is a unique solution to (A.6), which, it should be noted, does not depend on $R^{a}$. So this value of $L$, which we denote $L_{n}$, is the unique equilibrium level of lending in the absence of government guarantees.

The unique equilibrium ask rate, as determined by (A.5), is

$$
R_{n}^{a}=\frac{F}{s_{1}}\left[R^{*}+\psi^{\prime}\left(L_{n}\right)\right] .
$$

To complete the proof we need to show that $\underline{X}\left(L_{n}\right) \leq \bar{X}\left(L_{n}\right)$ so that a full hedge is feasible. Notice that

$$
\bar{X}=\bar{X}\left(L_{n}\right)=F\left[R^{*}+\psi^{\prime}\left(L_{n}\right)\right] L_{n}+\frac{R^{*} K}{\frac{1}{s_{1}}-\frac{1}{F}}
$$


and

$$
\underline{X}=\underline{X}\left(L_{n}\right)=F\left[R^{*}+\psi^{\prime}\left(L_{n}\right)\right] L_{n}-\frac{R^{*} K}{\frac{1}{F}-\frac{1}{s_{2}}} .
$$

Clearly $\bar{X}>\underline{X}$ so that a full hedge is feasible.

Finally, if $\lambda=\omega=0$, it is clear that the unhedged strategies $(x, L)=$ $\left[\underline{Y}(L), L_{n}\right]$, and $(x, L)=\left[\bar{Y}\left(L_{n}\right), L_{n}\right]$ are also equilibrium strategies.

\section{A.2. Proof of Proposition 5.2}

\section{A.2.1. Preliminaries}

Under government guarantees, the sets $\Omega_{1}, \Omega_{3}$ and $\Omega_{4}$ are defined in the same way as under no guarantees. The set $\Omega_{2}$ is defined differently. Notice that under guarantees, $R^{b}=R^{*}$ in $\Omega_{2}$.

\section{A.2.2. Solving the Bank's Problem}

We proceed as in the proof to Proposition 5.1. For $(x, L) \in \Omega_{1}$, expected profits are given by

$$
V_{1}(L)=R^{a} \frac{s_{1}}{F} L-R^{*} L-\psi(L)+(1-\delta) K .
$$

For $(x, L) \in \Omega_{2}$ expected profits are given by

$$
V_{2}=(1-p)\left[R^{a} L-R^{*} L-\psi(L)+(1-\delta) K+x\left(\frac{1}{F}-\frac{1}{s_{1}}\right)\right]
$$

In this case

$$
\frac{\partial V_{2}}{\partial x}=(1-p)\left(\frac{1}{F}-\frac{1}{s_{1}}\right)<0 .
$$

Thus, given a value of $L$, the bank will set $x$ to the minimum value it can take within $\Omega_{2}$ for that $L$, which, again, is $x=\underline{Y}(L)$. If we substitute $x=\underline{Y}(L)$ into the expression for expected profits we find

$$
V_{2}(L)=V_{1}(L)+p\left(R^{*} L-\frac{\omega}{1-\lambda}\right)
$$

Within $\Omega_{3}$, maximal expected profits for a given $L$ are again given by

$$
V_{3}(L)=V_{1}(L)-(1-p) \frac{\omega}{1-\lambda} .
$$


By the same argument we used in proving Proposition 5.1, we have $\max _{(x, L) \in \Omega_{3}} V<$ $\max _{(x, L) \in \Omega_{1}} V$.

Again, for any $(x, L) \in \Omega_{4}$ expected profits are $V=V_{4}=0$, so we have $\max _{(x, L) \in \Omega_{4}} V<\max _{(x, L) \in \Omega_{1}} V$. Thus we have eliminated $(x, L) \in \Omega_{3} \cup \Omega_{4}$ as equilibrium outcomes.

\section{A.2.3. Equilibrium}

In equilibrium $V=R^{*} K$. We cannot have $L=0$ in equilibrium since $V_{1}(0)=$ $(1-\delta) K-\psi(0)<R^{*} K$. There are two possibilities left to consider. First, there might be an equilibrium with $(x, L) \in \Omega_{1}$ in which the first-order condition, (A.5), is satisfied. This is an equilibrium in which banks are fully hedged. The ask rate must again be given by

$$
R_{n}^{a}=\frac{F}{s_{1}}\left[R^{*}+\psi^{\prime}\left(L_{n}\right)\right]
$$

and the level of expected profits must be

$$
V=\frac{s_{1}}{F} R_{n}^{a} L_{n}-R^{*} L_{n}-\psi\left(L_{n}\right)+(1-\delta) K=R^{*} K
$$

But notice that a bank facing $R_{n}^{a}$ could, by choosing $\left(x, L_{n}\right)=\left[\underline{Y}\left(L_{n}\right), L_{n}\right] \in \Omega_{2}$, obtain expected profits of

$$
V_{2}=V+p\left(R^{*} L_{n}-\frac{\omega}{1-\lambda}\right) .
$$

Our assumption on $\omega$ implies that $\left[\underline{Y}\left(L_{n}\right), L_{n}\right]$ is a feasible point within $\Omega_{2}$ and implies that $V_{2}>V$, so there cannot be an equilibrium with $(x, L) \in \Omega_{1}$.

To check whether there is an equilibrium with $(x, L) \in \Omega_{2}$, notice that we can first set $x=\underline{Y}(L)$, and then choose $L$. The lower bound on the values of $L$ which are feasible in $\Omega_{2}$ is the value of $L$ for which $\underline{X}(L)=\underline{Y}(L)$, which is $\underline{L}=\omega /\left[R^{*}(1-\lambda)\right]$. The largest value of $L$ which is feasible in $\Omega_{2}$ is one for which $\bar{V}_{2}(L)=0$ which we denote by $\bar{L}$. We assume, for the moment, that $\underline{L}<\bar{L}$, so that $\Omega_{2}$ is non-null. We choose $L \in(\underline{L}, \bar{L}]$ to maximize $V_{2}(L)$.

Differentiating $V_{2}$ with respect to $L$, we obtain the first order condition ${ }^{24}$

$$
\frac{s_{1}}{F} R^{a}-(1-p) R^{*}=\psi^{\prime}(L)
$$

\footnotetext{
${ }^{24}$ Since $V_{2}(\bar{L})=0, \bar{L}$ cannot be an equilibrium. Hence, any equilibrium within $\Omega_{2}$ must satisfy the first-order condition.
} 
In this case expected profits would be

$$
V=\psi^{\prime}(L) L-\psi(L)+(1-\delta) K-p \frac{\omega}{1-\lambda}=R^{*} K
$$

There is a unique solution, $L=L_{g}$, to (A.8) such that $L_{g}>L_{n}$. Notice that this implies $L_{g}>\underline{L}$, which confirms our initial assumption that $\underline{L}<\bar{L}$.

The unique equilibrium ask rate, as determined by (A.7), is

$$
R_{g}^{a}=\frac{F}{s_{1}}\left[(1-p) R^{*}+\psi^{\prime}\left(L_{g}\right)\right]
$$

The equilibrium hedge position of the bank is

$$
x_{g}=\underline{Y}\left(L_{g}\right) .
$$

\section{A.3. Proof of Proposition 6.1}

\section{A.3.1. Preliminaries}

Under the form of government guarantees described in the proposition, the sets $\Omega_{1}, \Omega_{2}$ and $\Omega_{4}$ are defined in the same way as in the proof to Proposition 5.2. The set $\Omega_{3}$ is defined as differently. Notice that when the government guarantees apply no matter which value of $S$ is realized then, in $\Omega_{3}, R^{b}=R^{*}$.

\section{A.3.2. Solving the Bank's Problem}

We proceed as in the proof to Proposition 5.2. For $(x, L) \in \Omega_{1}$, expected profits are given by

$$
V_{1}(L)=R^{a} \frac{s_{1}}{F} L-R^{*} L-\psi(L)+(1-\delta) K .
$$

For $(x, L) \in \Omega_{2}$ expected profits are again given by

$$
V_{2}(L)=V_{1}(L)+p\left(R^{*} L-\frac{\omega}{1-\lambda}\right) .
$$

For $(x, L) \in \Omega_{3}$ expected profits are given by

$$
V_{3}=p\left[R^{a} \frac{s_{1}}{s_{2}} L-R^{*} L-\psi(L)+(1-\delta) K+x\left(\frac{1}{F}-\frac{1}{s_{2}}\right)\right] .
$$


In this case

$$
\frac{\partial V_{3}}{\partial x}=p\left(\frac{1}{F}-\frac{1}{s_{2}}\right)>0 .
$$

Thus, given a value of $L$, the bank will set $x$ to the maximum value it can take within $\Omega_{3}$ for that $L$. This is $x=\bar{Y}(L)$. If we substitute $x=\bar{Y}(L)$ into the expression for expected profits we find

$$
V_{3}=V_{1}(L)+(1-p)\left(R^{*} L-\frac{\omega}{1-\lambda}\right)
$$

For any $(x, L) \in \Omega_{4}$ expected profits are $V=V_{4}=0$.

\section{A.3.3. Equilibrium}

In equilibrium $V=R^{*} K$. We cannot have $(x, L) \in \Omega_{4}$ in equilibrium for the same reason as in the previous propositions. There cannot be an equilibrium with $(x, L) \in \Omega_{1}$ using the same argument used in the proof of Proposition 5.2.

There might be an equilibrium with $(x, L) \in \Omega_{2}$. Notice that if there is such an equilibrium then it must be at $L_{g}$. But notice that

$$
V_{3}\left(L_{g}\right)=V_{2}\left(L_{g}\right)+(1-2 p)\left(R^{*} L_{g}-\frac{\omega}{1-\lambda}\right) .
$$

Since $p<1 / 2$ and $L_{g}>L_{n}$, we have $V_{3}\left(L_{g}\right)>V_{2}\left(L_{g}\right)=R^{*} K$. The fact that $V_{3}\left(L_{g}\right)>0$, implies that $L_{g}$ is feasible within $\Omega_{3}$. Hence $(x, L) \in \Omega_{2}$ cannot be an equilibrium.

To check whether there is an equilibrium with $(x, L) \in \Omega_{3}$, we differentiate $V_{3}$ with respect to $L$, to obtain the first order condition ${ }^{25}$

$$
\frac{s_{1}}{F} R^{a}-p R^{*}=\psi^{\prime}(L) .
$$

In this case expected profits would be

$$
V=\psi^{\prime}(L) L-\psi(L)+(1-\delta) K-(1-p) \frac{\omega}{1-\lambda}=R^{*} K
$$

There is a unique solution, $L=L_{u}$, to (A.10) such that $L_{u}>L_{g}>L_{n}$.

\footnotetext{
${ }^{25}$ An equilibrium within $\Omega_{3}$ must satisfy the first-order condition because the largest value of $L$ consistent with $(x, L) \in \Omega_{3}$, where $\underline{X}(L)$ intersects $\bar{Y}(L)$, is one at which $V_{3}=0$.
} 
The unique equilibrium ask rate, as determined by (A.9), is

$$
R_{u}^{a}=\frac{F}{s_{1}}\left[p R^{*}+\psi^{\prime}\left(L_{u}\right)\right]
$$

The equilibrium hedge position of the bank is

$$
x_{u}=\bar{Y}\left(L_{u}\right) .
$$

\section{A.4. Proof of Proposition 7.1}

If

$$
R^{a} L \Phi-R^{*} L-\psi(L)+(1-\delta) K+x\left(\frac{1}{F}-\frac{1}{S}\right) \geq 0, \quad \forall \Phi, S .
$$

the bank is fully hedged. This will be true whenever

$$
-\frac{\left(R^{a} \phi-R^{*}\right) L-\psi(L)+(1-\delta) K}{\frac{1}{F}-\frac{1}{s_{2}}}=\underline{x}_{H} \leq x \leq \bar{x}_{H}=\frac{\left(R^{a}-R^{*}\right) L-\psi(L)+(1-\delta) K}{\frac{1}{s_{1}}-\frac{1}{F}} .
$$

A sufficient condition for full hedging to be feasible is $\underline{x}_{H} \leq \bar{x}_{H}$. This is true whenever

$$
[1-p(1-\phi)] R^{a} L-R^{*} L-\psi(L)+(1-\delta) K \geq 0 .
$$

There are three other potentially feasible strategies for the bank.

The bank defaults in the devaluation state whenever $x<\underline{x}_{H}$. The lowest value of $x<\underline{x}_{H}$ that is feasible is one that reduces the residual value of the bank to zero when $S=s_{2}$ and $\Phi=\phi .{ }^{26}$ Notice that this is given by $\underline{x}$, the solution to

$$
(1-\lambda)\left[R^{a} L \phi+(1-\delta) K-\psi(L)+\underline{x}\left(\frac{1}{F}-\frac{1}{s_{2}}\right)\right]=\omega .
$$

Notice that defaulting in the devaluation state is feasible whenever $\underline{x}<\underline{x}_{H}$ which is equivalent to $\omega<(1-\lambda) R^{*} L$.

There are two distinct types of strategy for $\underline{x}<x<\underline{x}_{H}$. Under strategy $I$, the bank defaults when $S=s_{2}$ regardless of the value of $\Phi$. Under strategy $I I$, the bank defaults when $S=s_{2}$ and $\Phi=\phi$. Clearly, strategy $I$ involves more extreme values of $x$ than strategy $I I$. The lowest value of $x$ consistent with strategy $I I$ will

\footnotetext{
${ }^{26}$ Notice that the bank cannot reduce its residual value to zero regardless of the value of $\Phi$. If the bank set its residual value to zero when $S=s_{2}$ and $\Phi=1$, its residual value would be negative when $\Phi=\phi$.
} 
be one for which profits when $S=s_{2}$ and $\Phi=1$ are exactly zero, while profits when $S=s_{2}$ and $\Phi=\phi$ are negative. That is, it will be the value of $x$ such that

$$
R^{a} L-R^{b} L-\psi(L)+(1-\delta) K+x\left(\frac{1}{F}-\frac{1}{s_{2}}\right)=0
$$

when $R^{b}$ is set according to

$$
R^{*} L=(1-p q) R^{b} L+p q\left\{(1-\lambda)\left[R^{a} L \phi+(1-\delta) K-\psi(L)+x\left(\frac{1}{F}-\frac{1}{s_{2}}\right)\right]-\omega\right\}
$$

This value, which we denote by $x_{I I}$ is

$$
x_{I I}=\frac{p q \omega-\left\{[1-p q+p q(1-\lambda) \phi] R^{a} L-R^{*} L+(1-p q \lambda)[(1-\delta) K-\psi(L)]\right\}}{(1-p q \lambda)\left(\frac{1}{F}-\frac{1}{s_{2}}\right)} .
$$

Notice that both strategies $I$ and $I I$ are feasible if $\underline{x}<x_{I I}<\underline{x}_{H}$. Only strategy $I I$ is feasible if $x_{I I}<\underline{x}<\underline{x}_{H}$. Only strategy $I$ is feasible if $\underline{x}<\underline{x}_{H}<x_{I I}$. Notice that $x_{I I}<\underline{x}_{H}$ if

$$
\omega<\frac{(1-p q)(1-\phi) R^{a} L-p q \lambda R^{*} L}{p q} .
$$

Notice that $x_{I I}>\underline{x}$ if

$$
\omega<\frac{1-\lambda}{1-p q}\left[R^{*} L-(1-p q)(1-\phi) R^{a} L\right]
$$

Under strategy $I I I$, the bank defaults whenever $S=s_{1}$. This happens when it sets $\bar{x}_{H}<x \leq \bar{x}$ where

$$
(1-\lambda)\left[R^{a} L+(1-\delta) K-\psi(L)+\bar{x}\left(\frac{1}{F}-\frac{1}{s_{1}}\right)\right]=\omega .
$$

When full hedging is feasible, the bank's expected profits are

$$
V_{H}=[1-p q(1-\phi)] R^{a} L-R^{*} L-\psi(L)+(1-\delta) K .
$$

A bank using strategy $I$ (when it is feasible) defaults whenever $S=s_{2}$. Hence its expected profits are

$$
V_{I}=(1-p)\left[R^{a} L-R^{b} L-\psi(L)+(1-\delta) K+x\left(\frac{1}{F}-\frac{1}{s_{1}}\right)\right] .
$$


The borrowing rate under strategy $I$ is given by

$$
\begin{aligned}
R^{*} L= & (1-p) R^{b} L+p(1-)(1-q+q \phi) R^{a} L+ \\
& p\left\{(1-\lambda)\left[(1-\delta) K-\psi(L)+x\left(\frac{1}{F}-\frac{1}{s_{2}}\right)\right]-\omega\right\} .
\end{aligned}
$$

Combining this with (A.11) we have

$$
\begin{aligned}
V_{I}= & {[1-p+p(1-\lambda)(1-q+q \phi)] R^{a} L-R^{*} L+(1-p \lambda)[(1-\delta) K-\psi(L)]-} \\
& \lambda p\left(\frac{1}{F}-\frac{1}{s_{2}}\right) x-p w .
\end{aligned}
$$

Since $V_{I}$ is decreasing in $x$, the optimal strategy for the bank is to set $x=\underline{x}$. Combining this with (A.12) we have

$$
\begin{aligned}
V_{I} & =[1-p[q+\lambda(1-q)](1-\phi)] R^{a} L-R^{*} L+(1-\delta) K-\psi(L)-p \frac{\omega}{1-\lambda} \\
& =V_{H}-p \lambda(1-q)(1-\phi) R^{a} L-p \frac{\omega}{1-\lambda} .
\end{aligned}
$$

Hedging dominates strategy $I$.

A bank using strategy $I I$ (if it is feasible) defaults whenever $S=s_{2}$ and $\Phi=\phi$. Hence its expected profits are

$$
V_{I I}=(1-p q)\left[R^{a} L-R^{b} L-\psi(L)+(1-\delta) K\right]-p q\left(\frac{1}{F}-\frac{1}{s_{2}}\right) x
$$

The borrowing rate under strategy $I I$ is given by

$$
R^{*} L=(1-p q) R^{b} L+p q\left\{(1-\lambda)\left[R^{a} L \phi+(1-\delta) K-\psi(L)+x\left(\frac{1}{F}-\frac{1}{s_{2}}\right)\right]-\omega\right\} .
$$

Combining this with (A.13) we have

$$
\begin{aligned}
V_{I I}= & {[1-p q+p q(1-\lambda) \phi] R^{a} L+(1-p q \lambda)[(1-\delta) K-\psi(L)]-R^{*} L-} \\
& \lambda p q\left(\frac{1}{F}-\frac{1}{s_{2}}\right) x-p q \omega
\end{aligned}
$$

Since $V_{I I}$ is decreasing in $x$ the optimal strategy for the bank is to set $x$ equal to the smallest value consistent with strategy $I I$. This will be $x=\max \left\{\underline{x}, x_{I I}\right\}$. Combining $x=\underline{x}$ and (A.14) we obtain

$$
\begin{aligned}
V_{I I} & =[1-p q(1-\phi)] R^{a} L-R^{*} L-\psi(L)+(1-\delta) K-p q \frac{\omega}{1-\lambda} \\
& =V_{H}-p q \frac{\omega}{1-\lambda} .
\end{aligned}
$$


This means that for $x=\max \left\{\underline{x}, x_{I I}\right\}$ we have $V_{I I} \leq V_{H}-p q /(1-\lambda)$ since $V_{I I}$ is decreasing in $x$. Thus, hedging dominates strategy $I I$.

A bank using strategy $I I I$ defaults whenever $S=s_{1}$. Hence its expected profits are

$$
V_{I I I}=p\left[(1-q+q \phi) R^{a} L-R^{b} L-\psi(L)+(1-\delta) K+x\left(\frac{1}{F}-\frac{1}{s_{2}}\right)\right]
$$

The borrowing rate under strategy $I I I$ is given by

$$
R^{*} L=p R^{b} L+(1-p)\left\{(1-\lambda)\left[R^{a} L+(1-\delta) K-\psi(L)+x\left(\frac{1}{F}-\frac{1}{s_{1}}\right)\right]-\omega\right\}
$$

Combining this with (A.15) we have

$$
\begin{aligned}
V_{I I I}= & {[p(1-q+q \phi)+(1-p)(1-\lambda)] R^{a} L-R^{*} L+[1-\lambda(1-p)][(1-\delta) K-\psi(L)]-} \\
& \lambda(1-p)\left(\frac{1}{F}-\frac{1}{s_{1}}\right) x-(1-p) \omega
\end{aligned}
$$

The optimal strategy for the bank is to set $x=\bar{x}$. Combining this with (A.16) we have

$$
\begin{aligned}
V_{I I I} & =[1-p q(1-\phi)] R^{a} L-R^{*} L+(1-\delta) K-\psi(L)-(1-p) \frac{\omega}{1-\lambda} \\
& =V_{H}-(1-p) \frac{\omega}{1-\lambda} .
\end{aligned}
$$

Hedging dominates strategy $I I I$.

\section{A.5. Proof of Proposition 7.2}

As in the proof to Proposition 7.1 the bank is fully hedged if $\underline{x}_{H} \leq x \leq \bar{x}_{H}$ and there are three other potentially feasible strategies for the bank.

The bank defaults in the devaluation state whenever $\underline{x} \leq x<\underline{x}_{H}$. Notice that defaulting in devaluation state is feasible because $\omega<(1-\lambda) R^{*} L$ implies $\underline{x}<\underline{x}_{H}$. Strategies $I$ and $I I$ are defined as before, but, because $R^{b}=R^{*}, x_{I I}$ is different. It is the lowest value of $x$ for which profits when $S=s_{2}$ and $\Phi=1$ are exactly zero, while profits when $S=s_{2}$ and $\Phi=\phi$ are negative. Since, with guarantees, $R^{b}=R^{*}$, it will be the value of $x$ such that

$$
R^{a} L-R^{*} L-\psi(L)+(1-\delta) K+x\left(\frac{1}{F}-\frac{1}{s_{2}}\right)=0 .
$$


This value, which we denote by $x_{I I, g}$ is

$$
x_{I, g}=-\frac{R^{a} L-R^{*} L+(1-\delta) K-\psi(L)}{\frac{1}{F}-\frac{1}{s_{2}}} .
$$

It can be shown that $x_{I I, g}<\underline{x}_{H}$ so that strategy $I I$ is always feasible. Only strategy $I I$ is feasible if $x_{I I, g}<\underline{x}<\underline{x}_{H}$. Notice that both strategies $I$ and $I I$ are feasible if $\underline{x}<x_{I I, g}<\underline{x}_{H}$, or, equivalently, if

$$
\omega<(1-\lambda)\left[R^{*} L-(1-\phi) R^{a} L\right] .
$$

Under strategy $I I I$, the bank defaults whenever $S=s_{1}$. This happens when it sets $\bar{x}_{H}<x \leq \bar{x}$.

When fully hedged the bank's expected profits are

$$
V_{H}=[1-p q(1-\phi)] R^{a} L-R^{*} L-\psi(L)+(1-\delta) K .
$$

A bank using strategy $I$ defaults whenever $S=s_{2}$. Hence its expected profits are

$$
V_{I}=(1-p)\left[R^{a} L-R^{*} L-\psi(L)+(1-\delta) K+x\left(\frac{1}{F}-\frac{1}{s_{1}}\right)\right] .
$$

The optimal strategy for the bank is to set $x$ to the lowest value it can take on, $x=\underline{x}$. Combining this with (A.18) we have

$$
\begin{aligned}
V_{I} & =[1-p(1-\phi)] R^{a} L-(1-p) R^{*} L-\psi(L)+(1-\delta) K-p \frac{\omega}{1-\lambda} \\
& =V_{H}+p\left[R^{*} L-(1-\phi) R^{a} L-\frac{\omega}{1-\lambda}\right]+p q(1-\phi) R^{a} L .
\end{aligned}
$$

When strategy $I$ is feasible, (A.17) holds, which implies $V_{I}>V_{H}$.

A bank using strategy $I I$ defaults whenever $S=s_{2}$ and $\Phi=\phi$. Hence its expected profits are

$$
V_{I I}=(1-p q)\left[R^{a} L-R^{*} L-\psi(L)+(1-\delta) K\right]-p q\left(\frac{1}{F}-\frac{1}{s_{2}}\right) x
$$

The optimal strategy for the bank is to set $x$ to the lowest value it can take on, which is $x_{I I, g}$ if (A.17) holds and is $\underline{x}$ otherwise. Combining $x=x_{I I, g}$ with (A.19) we have

$$
\begin{aligned}
V_{I I} & =R^{a} L-R^{*} L-\psi(L)+(1-\delta) K \\
& =V_{H}+p q(1-\phi) R^{a} L .
\end{aligned}
$$


Combining $x=\underline{x}$ with (A.19) we have

$$
\begin{aligned}
V_{I I} & =[1-p q(1-\phi)] R^{a} L-(1-p q) R^{*} L-\psi(L)+(1-\delta) K-p q \frac{\omega}{1-\lambda} \\
& =V_{H}+p q\left(R^{*} L-\frac{\omega}{1-\lambda}\right) .
\end{aligned}
$$

To summarize, when (A.17) holds $V_{I}>V_{I I}>V_{H}$, so strategy $I$ dominates. When (A.17) does not hold, strategy $I$ is not feasible but $V_{I I}>V_{H}$. Hence, full hedging is always dominated.

As in the proof to Proposition 7.1 a bank using strategy $I I I$ has expected profits

$$
V_{I I I}=V_{H}-(1-p) \frac{\omega}{1-\lambda} .
$$

Hedging dominates strategy $I I I$. 
Figure 1

Feasible Choices of $(x, L)$

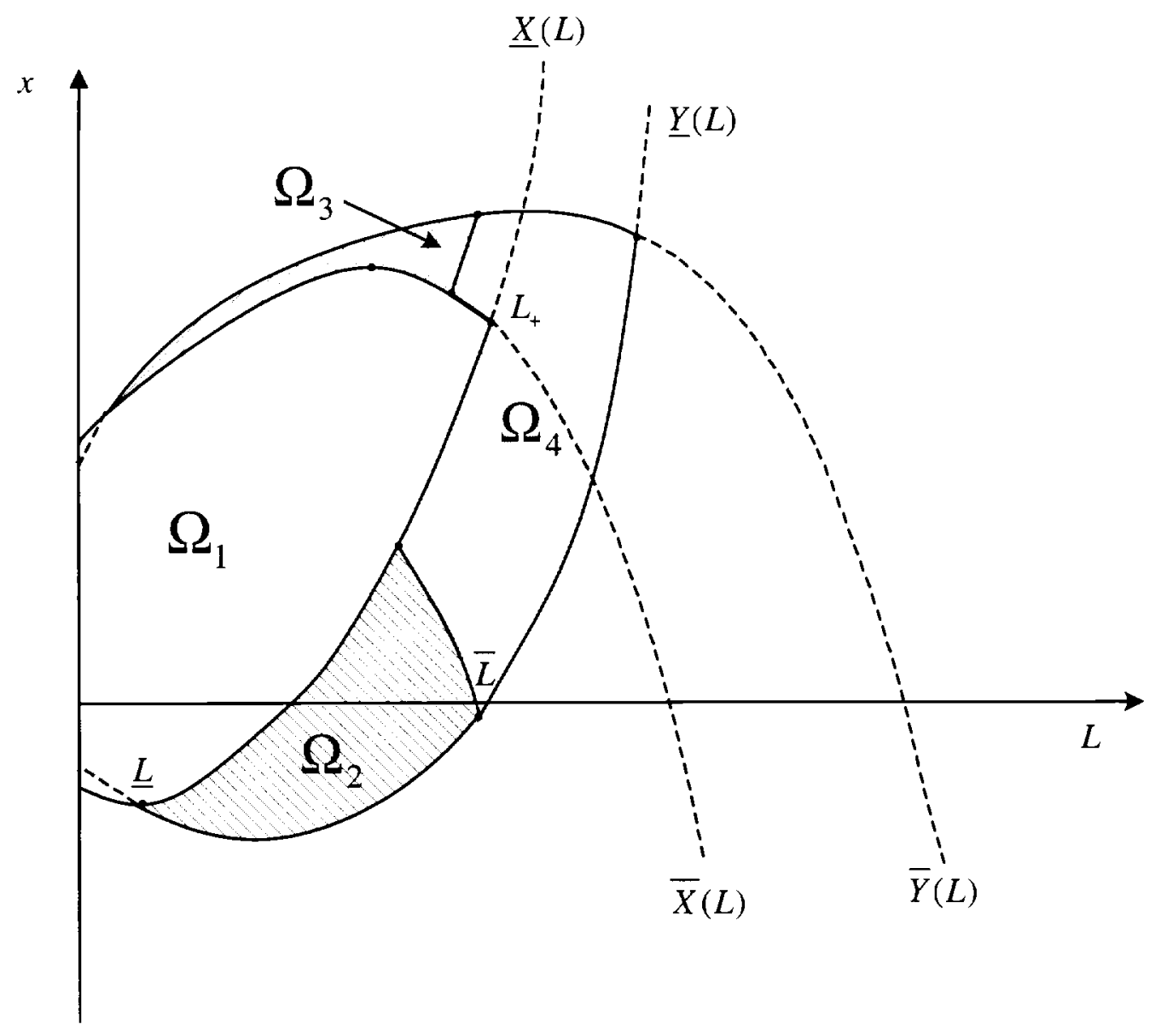

